\title{
The Effect of Data Generalization on the Prediction of Hydrologic Response
}

\author{
By Cheryl A. Hallam
}

Open-File Report 93-354 


\section{TABLE OF CONTENTS}

LIST OF TABLES $\ldots \ldots \ldots \ldots \ldots \ldots \ldots \ldots \ldots \ldots \ldots$ iv

LIST OF FIGURES $\ldots \ldots \ldots \ldots \ldots \ldots \ldots \ldots \ldots \ldots \ldots$

ABSTRACT $\ldots \ldots \ldots \ldots \ldots \ldots \ldots \ldots \ldots \ldots \ldots \ldots \ldots \ldots \ldots \ldots \ldots \ldots$

Chapter

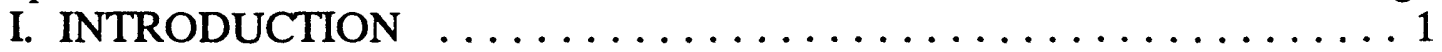

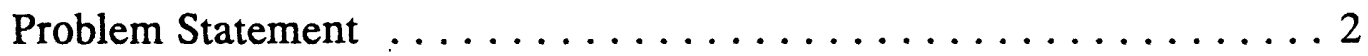

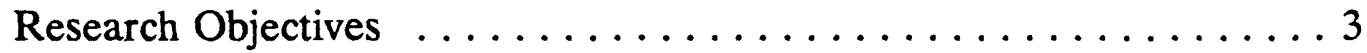

II. THE EFFECT OF GENERALIZATION ON HYDROLOGIC MODELS

Hydrology/Hydrologic Models .................4

The Precipitation-Runoff Modeling System $\ldots \ldots \ldots \ldots \ldots \ldots$

The Role of Slope and Aspect in PRMS $\ldots \ldots \ldots \ldots \ldots \ldots \ldots$

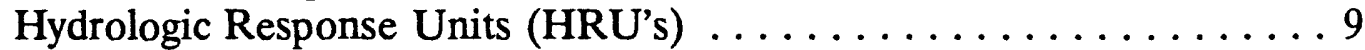

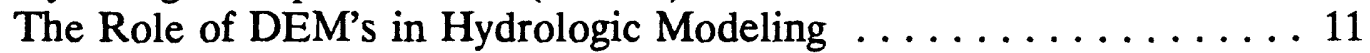

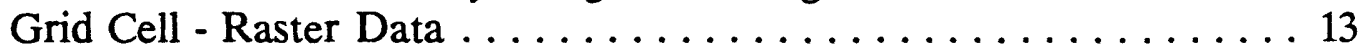

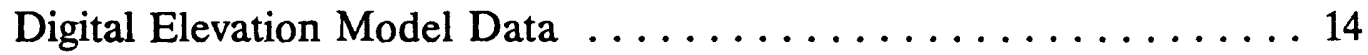

Generalization ......................... 15

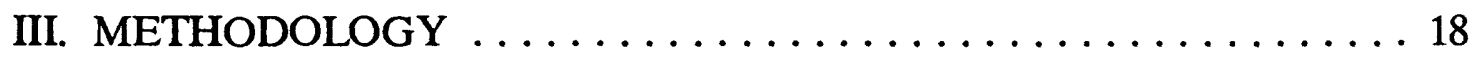

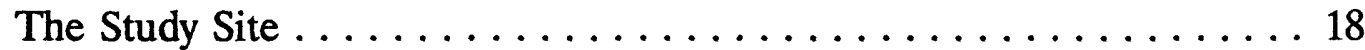

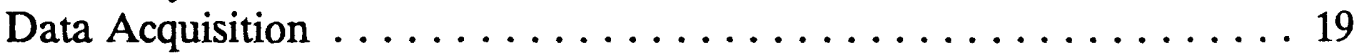

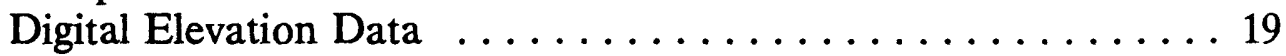

Basin Discharge ...................... 20

Precipitation Data .................... 20

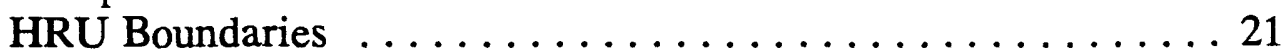

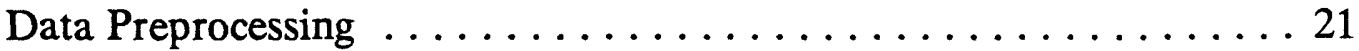

Generation of Topographic Statistics .............. 23

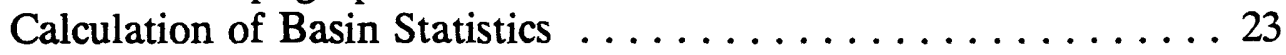

Calculation of HRU Statistics $\ldots \ldots \ldots \ldots \ldots \ldots \ldots \ldots$

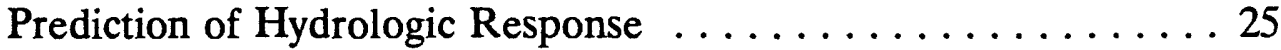

Comparison of Model Results . . . . . . . . . . . . 25 


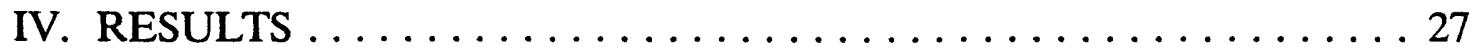

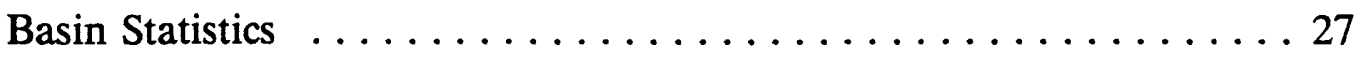

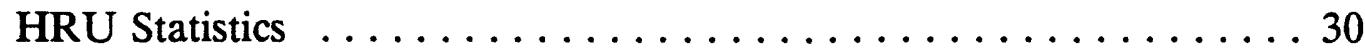

Comparison of Model Results . . . . . . . . . . . . . 42

V. CONCLUSION $\ldots \ldots \ldots \ldots \ldots \ldots \ldots \ldots \ldots \ldots \ldots \ldots \ldots \ldots \ldots \ldots$

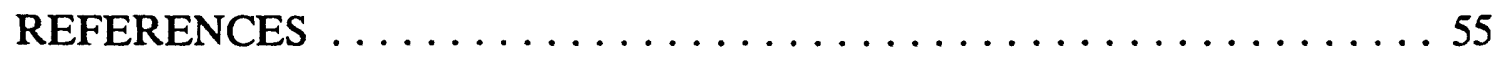




\section{LIST OF TABLES}

Table Page

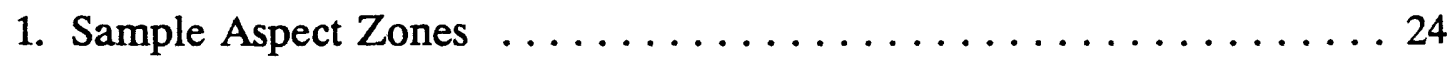

2. Descriptive Statistics for the East River Basin - Elevation $\ldots \ldots \ldots 28$

3. Descriptive Statistics for the East River Basin - Slope $\ldots \ldots \ldots \ldots 28$

4. Elevation, Slope and Aspect Correlations - East River Basin . . . . . 29

5. Dominant Aspect for each HRU at each Resolution $\ldots \ldots \ldots \ldots 38$

6. T-Statistics for the HRU Slope and Aspect Estimates $\ldots \ldots \ldots \ldots 4$

7. Regression Statistics for the HRU Elevation and Slope Data ..... 42

8. Runoff Correlation Matrix $\ldots \ldots \ldots \ldots \ldots \ldots \ldots \ldots \ldots \ldots$

9. Changes in Predicted Annual Runoff for $1972-1989 \ldots \ldots \ldots$. . . . 47

10. Changes in Predicted Monthly Runoff for $1972-1989 \ldots \ldots$. . . . 48

11. Results of the Paired-Difference t-test for Annual Runoff $\ldots . \ldots .49$

12. Results of the Paired-Difference t-test for Monthly Runoff $\ldots \ldots \ldots 50$ 


\section{LIST OF FIGURES}

$\begin{array}{ll}\text { Figure } & \text { Page }\end{array}$

1. Gunnison River Basin Location Map . . . . . . . . . . . . 19

2. East River Basin Location Map $\ldots \ldots \ldots \ldots \ldots \ldots \ldots \ldots \ldots$

3. HRU Boundaries for the East River Basin $\ldots \ldots \ldots \ldots \ldots \ldots 22$

4. Elevation, Slope and Aspect Correlation Graph . . . . . . . . . 29

5. Mean Elevation and Slope Graphs for each HRU $\ldots \ldots \ldots \ldots 31$

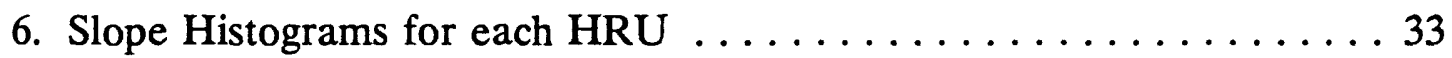

7. Slope Histograms for HRU 4 at each Resolution $\ldots \ldots \ldots \ldots \ldots 35$

8. Slope Histograms for HRU 14 at each Resolution $\ldots \ldots \ldots \ldots \ldots$

9. Slope Histograms for HRU 1 at each Resolution $\ldots \ldots \ldots \ldots \ldots 37$

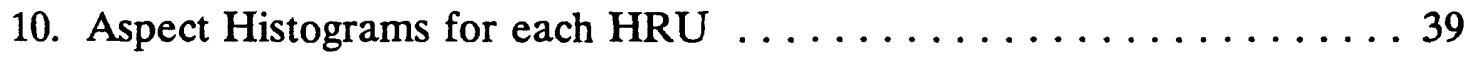

11. Hydrographs of Observed and Predicted Runoff $\ldots \ldots \ldots \ldots$

12. Plot of Predicted versus Observed Monthly Runoff . . . . . . . . 44

13. Plot of Predicted Runoff -100 versus 1000 meter . . . . . . . . 46

14. Plot of Model and Resolution Error $\ldots \ldots \ldots \ldots \ldots \ldots \ldots \ldots$ 


\begin{abstract}
As more land-based process information is included in the predominantly atmospheric general circulation models (GCM), the generalization of descriptions of the Earth's surface contained in digital elevation models (DEM) and other land characterization data sets is becoming more important. Many lower resolution data bases used in global models are being assembled from groups of higher resolution regional data bases.

As the regional effects of global change are studied, and the information generated by continental and global models provides data sources for the regional hydrologic models, the validity of those regional models' predictions may come into question. Although efforts are being made to minimize the amount of information lost in the generalization process, some loss is inevitable. It is important to understand the effect that such an information loss will have on the models in which these data are used.

This research project examined the sensitivity of a widely used precipitationrunoff model to data generalization. A controlled experiment was conducted to determine how runoff predictions were affected by changes in the spatial resolution of elevation-based input parameters.

Preliminary results suggest that, for the 17 years tested, the elevation data resolution had a significant effect on the prediction of monthly runoff totals, but the annual runoff totals were unaffected by generalization of the elevation data from 100 to 1,000 meters. In addition, the changes in predicted monthly runoff showed a seasonal pattern. If such runoff differences hold up under statistical tests, they could suggest serious seasonal prediction errors when input data are generalized.
\end{abstract}




\section{INTRODUCTION}

Data resolution has been of interest since the development of the first digital spatial data. (Tobler 1966) The interest has focused on: 1 ) its ability to accurately represent the area to be mapped; 2) the ability of the available technology (software and hardware) to accommodate the data; and 3) the data structure which would best maintain the information in the most usable form.

The computerization of physically-based process models has also raised questions about data resolution and scale because of its effect on model results, especially in the global change modeling community:

The atmospheric, hydrologic, and terrestrial components of the Earth system operate on different time and space scales. Resolving these scaling incongruities is one of the major challenges facing hydrologists, ecologists and atmospheric scientists alike. Integration across these scales cannot be achieved with a simple, additive coupling. Thus, numerical models which describe, simulate or predict behavior of ecohydrologic processes require explicit linkage to ensure that data flow between the model components contains specific information at the appropriate scale (International Geophysical Biophysical Programme 1991).

As more emphasis is placed on the inclusion of land-based process information in the atmospheric general circulation models (GCM), the generalization of available descriptions of the earth's surface contained in digital elevation models (DEM) and other land characterization data sets is becoming more important. This generalization is a process by which the spatial resolution of a data set is decreased while as much information as possible is retained (Muller 1991). Many small scale data bases are currently being generalized from groups of higher resolution regional data bases for use in global models (Hutchinson 1991). For example, the U. S. Geological Survey (USGS) is currently involved in interagency and international projects to produce data bases containing national, continental, and global scale soils data (Bliss 1990); elevation data (Jenson 1992); and land cover and vegetation data (Loveland 1991). In all three cases, efforts are being made to minimize the information lost in the generalization process, but some information loss is inevitable. These data bases are currently being tested in meso(intermediate-) and large-scale GCM's to add a more realistic representation of surface processes and to produce better spatial representations of the potential global climate changes (Steyaert and others 1993).

The work of integrating all of these data and models is getting under way, and the technology recognized as the primary tool is the geographic information system (GIS). Its strong role can be seen in the growing number of conferences on 
the subject. Conferences such as the International Conferences / Workshops on Integrating Geographic Information Systems and Environmental Modeling (September 1991 and 1993) and the Symposium on Geographic Information Systems and Water Resources (March 1993) describe much of the current work. In his keynote address published in the proceedings of the meeting in March 1993, Dallas Peck (1993) discussed the growing role of GIS "as a problem-solving tool, as a new method of scientific visualization, and as a technique for encouraging cross-discipline interaction..."

Much of the current global climate change research predicts possible changes in both temperature and precipitation in the next few decades as a result of human activities. The results of these changes are distributed over both time and space, as well as quantity (Liverman and O'Brien 1989; Gates 1985). Changes in the timing of high and low temperatures may lead to changes in the availability of melt water from snow and ice accumulations (Gleick 1987a). Changes in the timing of precipitation throughout the year may decrease the level of reservoirs which could increase the intensity and duration of summer drought conditions (Cohen 1986; Gleick 1987a). Regional water cycles could be affected by such changes, and neighboring basins could be affected differently based on their physical characteristics and location relative to physical barriers such as mountains (Jeton and Smith 1992; Leavesley, Branson and Hay 1992; Moreau unpublished). If such changes do occur, an understanding of the movement and distribution of water on a regional basis will be even more important than it is now. Hydrologic models play an important role in water resource planning activities, and it will become increasingly important to understand the sensitivity of regional basins to potential global climate changes (Gleick, 1987b). These issues are closely related to spatial resolution issues as the modelers attempt to link global-, meso- and regional-scale models to assess the effects of global changes on regional systems.

The International Geosphere-Biosphere Programme (IGBP) study (IGBP 1991) suggested three possible ways to deal with these resolution and scale issues. The first was to run the GCM's on much higher resolution data. The second was to run nested meso-scale models at higher resolutions. The third was to interpret the GCM results according to relationships developed on a local level. Scientists (IGBP 1991) suggest the most practical solution may be a combination of the second and third options. They also mention the importance of including in the modeling process the hydrologic interactions between soil moisture, vegetation, and evapotranspiration, as well as runoff information (IGBP 1991).

\section{Problem Statement}

As regional effects of global changes are studied, and results from continental and global model become data sources for regional hydrologic models, the validity of those regional model results may come into question. When this happens, it will be important to know how the use of generalized global data in regional models affects their results. Although it is clear that any generalization of a spatial data set results in a loss of information, it is not clear what effect that information loss may have on the results of the models in which these data are used. 


\section{Research Objectives}

This research examines the sensitivity of a widely used precipitation-runoff model to the resolution of the elevation-based input data, by conducting a controlled experiment to determine the influence of the spatial resolution of elevation-based input parameters on the model, for a drainage area in the headwaters of the Colorado River. Although the research will specifically target the spatial resolution of elevation-based model input, it should be realized that there are two other resolutions which are involved in the operation of the model. The model itself calculates runoff at a range of temporal resolutions as it interprets the rainfall and temperature information which is collected and input at another temporal resolution. In order to keep the other resolutions from interfering with the study of the resolution of the elevation parameters, the resolution of the other input data were held constant during the operation of the model.

Preliminary tests of the sensitivity of hydrologic models to one measure of spatial resolution have indicated that soils (Salisbury 1992) and annual evapotranspiration predictions (Williams 1992), have little effect on model results. Another comparison of elevation-based parameters (generated from data sets compiled at different resolutions) suggested that the difference in model results is significant (Wolock and Price 1992).

This research isolates elevation resolution by varying only mean elevation, mean slope, and dominant aspect parameters to perform a controlled test of the effect of resolution on predicted runoff. 


\title{
THE EFFECT OF GENERALIZATION ON HYDROLOGIC MODELS
}

\author{
Hydrology and Hydrologic Modeling
}

It has been suggested that the Greek philosophers were the first serious students of hydrology, but the first recorded measurements of rainfall and surface flow were made in the seventeenth century on the Seine (Biswas 1975). Developments during the nineteenth century included the first systematic stream gaging. Advances continued into the twentieth century, with funding coming from many of the government agencies which had been formed in the previous century. The introduction of digital computers into hydrology has provided one of the greatest advances in the field (Bedient 1988).

In the 1970's, Linsley (1975) realized the importance of computers to the running of models and the importance of the inclusion of physical parameters in the calibration of hydrologic models. He also saw the need for the development of a model which would be applicable to a wide range of basins because of its ability to use the physical parameters of differing basins in conjunction with its general principles to project runoff. It is important to realize, however, as did the Countess of Lovelace, that the model is only as good as the thinking and data that go into it (Fleming 1975).

Computers have provided a platform for the operation of large hydrologic models. These systems can now be used to compare different basins or portions of basins and to study basin response over time. They have "helped direct the collection of the hydrologic data to calibrate or 'match' the models against observation. In the process, the understanding of the hydrologic system has been greatly advanced" (Bedient 1988).

The existence of these computerized models has made it possible to process the large quantities of data required to replicate the functions of a drainage basin. This advance, in turn, has made it possible to study the regional hydrologic cycle, project past and future events, and apply that knowledge to global studies (Chow 1975).

Work currently in progress in the hydrologic modeling community includes the use of expert systems for model calibration (Lumb and others 1992) and the use of Geographic Information Systems (GIS) and digital data to calculate many of the parameters required to run the hydrologic models (Smith and Reece 1992; Gunderson 1992; Ryan 1992; Battaglin and others 1992, 1993; Jeton and Smith 1993; Eash 1993; Martz and Garbrecht 1993; Garbrecht and Martz 1993; Faucher and others 1993; Chairat and Delleur 1993; Luker and others 1993). Systems are also under development to facilitate the flow of data from the GIS to the model, as well as, from the model back to the GIS for display, storage, manipulation, and analysis before later input to the model (Leavesley and others 1992b). This linkage 
will provide the modeling community with a very important tool for the study of basin changes over time. An effort is also being made to develop and upgrade existing models to operate interactively providing friendly user interfaces (Leavesley and others 1992b).

The Precipitation-Runoff Modeling System

The hydrologic model selected for use in this study is the PrecipitationRunoff Modeling System (PRMS). It is a water balance and energy balance model described in the following excerpt from its documentation:

PRMS is designed to function either as a lumped- or distributedparameter type model and will simulate both mean daily flows and stormflow hydrographs. PRMS components are designed around the concept of partitioning a watershed into units on the basis of characteristics such as slope, aspect, vegetation type, soil type, and precipitation distribution. Each unit is considered homogeneous with respect to its hydrologic response and is called a hydrologic response unit (HRU). A water balance and an energy balance are computed daily for each HRU. The sum of the responses of all HRU's, weighted on a unit-area basis, produces the daily system response and streamflow from the watershed (Leavesley and others 1983).

This model was developed from the model detailed by Leavesley (1973). Stormflow computations were added based on the Distributed Routing RainfallRunoff Model (DR3M) (Dawdy and others 1978). PRMS has become one of the principal models used by USGS hydrologists. It was selected for use in this research for the following reasons: 1) It permits subdivision of the basin into separate spatial units to better represent basin heterogeneity. 2) It utilizes elevation information (especially slope and aspect) in its calculation of flow for each of the subbasins being modeled. 3) It is a nonproprietary system. 4) It was enhanced by USGS personnel who provide convenient assistance. 5) It is currently in use by its developers on a basin in Colorado which would lend itself well to this research. 6) It is one of the standard models widely used by USGS and non-USGS hydrologists in studies from Maine to California (Parker and Norris 1989; Fontaine 1989; Bower 1985; Cary 1984; Carey and Simon 1984). Its popularity and utility to hydrologists is such that work is in progress on an interactive version of the model in a menu driven format with graphics capabilities to display operator-selected variables and hydrographs as the model runs (Leavesley and others 1992b). Elevation, slope, and aspect data describing each of the hydrologic response units (HRU) are used by the model to calculate evapotranspiration and snow melt, which are quite important in the mountainous, semiarid basin in which the model has been applied. The following excerpts from the PRMS documentation (Leavesley and others 1983) describe the uses of elevation-based data in the model: 
Elevation (in the form of mean HRU elevation) is used to adjust observed or estimated temperatures to appropriate values for the elevation of each HRU. Those data may be input in either Fahrenheit $\left({ }^{\circ} \mathrm{F}\right)$ or Celsius $\left({ }^{\circ} \mathrm{C}\right)$, but must be consistent through a simulation. Observed daily maximum (TMX) and minimum (TMN) air temperatures are adjusted to account for differences in elevation and slope-aspect between the climate station and each HRU. A correction factor (TCRX) for adjusting TMX for each HRU is computed for each month (MO) by:

where:

$$
\operatorname{TCRX}(\mathrm{MO})=\left[\mathrm{TLX}(\mathrm{MO}){ }^{*} \mathrm{ELCR}\right]-\mathrm{TXAJ}
$$

TLX is the maximum temperature lapse rate, in degrees per 1,000 feet change in elevation for month MO;

ELCR is the mean elevation of an HRU minus the elevation of the climate station, in 1,000's of feet; and

TXAJ is an average difference in maximum air temperature between a horizontal surface and that of a surface with the slope-aspect of the HRU.

A correction factor [TCRN(MO)] for adjusting TMN for each HRU is computed monthly with an equation of the same form as equation 1 , using the monthly minimum temperature lapse rate $[\mathrm{TLN}(\mathrm{MO})]$ and minimum temperature slope-aspect correction (TNAJ).

Adjusted daily maximum air temperature (TM) for each HRU is computed by:

$$
\mathrm{TM}=\mathrm{TMX}-\mathrm{TCRX}(\mathrm{MO})
$$

Adjusted daily minimum air temperature (TN) for each HRU is computed using an equation of the same form as equation 2 and the variables TMN and TCRN(MO).

The means of those temperature values are then used to estimate evapotranspiration for the HRU's using the procedure developed by Jensen and Haise (1963), in which potential evapotranspiration (PET) (in. per day) is computed by:

where:

$$
\text { PET }=\mathrm{CTS}(\mathrm{MO}){ }^{*}(\mathrm{TAVF}-\mathrm{CTX}){ }^{*} \mathrm{RIN}
$$

CTS is a coefficient for the month MO,

TAVF is the daily mean air temperature $\left({ }^{\circ} \mathrm{F}\right)$,

CTX is a coefficient, and

RIN is daily solar radiation expressed in inches of evaporation potential. 
Because the procedure tends to underestimate winter month PET, the ability to change CTS is provided. For the warmer months of the year, constant values for CTS and CTX can be estimated using regional air temperature, elevation, vapor pressure, and vegetation data (Jensen and others 1969). For aerodynamically rough crops, which are assumed to include forests, CTS is computed for the watershed by:

where:

$$
\mathrm{CTS}=\left[\mathrm{C} 1+\left(13.0^{*} \mathrm{CH}\right)\right]^{-1}
$$

$\mathrm{C} 1$ is an elevation correction factor, and

$\mathrm{CH}$ is a humidity index.

$\mathrm{C} 1$ is computed by:

where:

$$
\mathrm{C} 1=68.0-\left[3.6^{*}(\mathrm{E} 1 / 1,000)\right]
$$

E1 is the mean elevation of the watershed ( $\mathrm{ft})$.

$\mathrm{CH}$ is computed by:

where:

$$
\mathrm{CH}=\left(50 /\left(\mathrm{e}_{2}-\mathrm{e}_{1}\right)\right)
$$

$e_{2}$ is the saturation vapor pressure $(\mathrm{mb})$ for the mean maximum air temperature for the warmest month of the year, and

$e_{1}$ is the saturation vapor pressure $(\mathrm{mb})$ for the mean minimum air temperature for the warmest month of the year.

CTX is computed for each HRU by:

where:

$$
\text { CTX }=27.5-0.25^{*}\left(e_{2}-e_{1}\right)-(E 2 / 1,000)
$$

E2 is the mean elevation of the HRU (ft).

Actual evapotranspiration (AET) is the computed rate of water loss which reflects the availability of water to satisfy PET (in. per day). When available water is nonlimiting, AET equals PET. PET is first satisfied from interception storage, retention storage on impervious areas, and evaporation and sublimation from snow surfaces. Remaining PET demand then is applied to the soil-zone storage.

The Role of Slope and Aspect in PRMS (excerpted from Leavesley and others 1983)

Slope is used along with aspect to adjust solar radiation received by each HRU, or solar radiation plane. Observed daily shortwave radiation 
(ORAD), expressed in langleys per day (ly/d) is used in snow melt computations ... . ORAD, measured on a horizontal surface, is adjusted to estimate SWRD, the daily shortwave radiation received on the slope/aspect combination of each HRU. SWRD is computed by:

where

$$
\text { SWRD }=\text { ORAD } *(D R A D / \text { HORAD })
$$

DRAD is the daily potential solar radiation for the slope and aspect of an HRU (ly), and

HORAD is the daily potential solar radiation for a horizontal surface (ly).

DRAD is calculated directly from the mean latitude, slope and aspect (azimuth of slope) information describing each HRU, using algorithms developed by Swift (1976) which produce daily values measured in langleys.

The proper calculation of solar radiation is very influential in the calculation of net shortwave radiation (SWN), measured in calories:

where

$$
\text { SWN }=\mathrm{SWRD}^{*}(1.0-\mathrm{ALB}) * \mathrm{TRNCF}
$$

ALB is the albedo of the snowpack surface, and TRNCF is the transmission coefficient for the vegetation canopy over the snowpack and is a function of one of the four land cover categories (bare, grass, shrubs, trees) combined with the summer or winter cover density.

The net shortwave radiation (calories) is then used to calculate the energy balance at the air-snow interface (CALN) for each 12 hour period:

where

$$
\mathrm{CALN}=\mathrm{SWN}+\mathrm{LWN}+\mathrm{CEN}
$$

LWN is net long wave radiation (calories), and

CEN is an approximation of the convection-condensation energy terms involving phase changes and mass transfers (calories).

When the 12-hour energy balance (CALN) is positive, this energy is assumed to melt snow in the surface layer. Snow melt transports heat into the snowpack by mass transfer. Snow melt (SMLT), measured in inches, is computed by:

where

$$
\text { SMLT }=\text { CALN } / 203.2
$$

203.2 is the number of calories required to melt 1 inch of water-equivalent ice at $0^{\circ} \mathrm{C}$. 


\section{Hydrologic Response Units (HRU's)}

HRU's are spatial subunits of basins within which the physical characteristics are determined to be the same or to fall within a previously chosen range. In some cases, these units are required to be contiguous, which usually means that they are subbasins or portions of subbasins split along a stream line. In other cases, each HRU is a set of polygons defined by specific criteria. In either case, a set of criteria is used to determine the boundaries. For each HRU, the parameters required for the operation of the model are calculated and a hydrologic response for each HRU is generated by the model.

Although the original intent of the model was to use hydrologically homogeneous subareas, the subareas used by it and similar models can be of two types: 1) subareas of similar hydrologic response; or 2) the result of a regular subdivision of the basin into equal size areas. The first represents areas of similar hydrologic response as described above. The second considers the areas to be of similar hydrologic response because of the proximity of their content area or because they divide the basin into small enough areas to represent the heterogeneity in the basin and not miss any significantly unique areas (Becker and Pfeutzner 1990).

In practice, the decision on how to generate HRU's can depend on the type of model to be used, the type of study being carried out, data availability, or simply the preference of the researcher based on their knowledge of the study area and the model to be used. Operational methods for delineation of HRU's can be divided into the following three categories:

Manual. In this technique the researcher uses available topographic and other maps to outline the basin boundaries and the HRU boundaries within the basin. It is a process that relies entirely on the researcher for an understanding of the particular basin to be studied and an ability to draw the boundaries. The process is also affected by the philosophy of the researcher, who may favor the use of areas which are subbasins of the whole basin to be modeled, the use of aspect zones, vegetation zones, elevation zones, or some combination of the above, based on personal judgement.

Automated. Automated procedures for defining HRU's can be based on physiographic features or systematic grids. Automated physiographic approaches rely totally on a set of algorithms to determine combinations of the physical variables describing the basin and a previously set series of ranges in those variables to determine which areas of the basin have similar hydrologic responses. For example, HRU's may be based on the automatic generation of subbasins split along stream lines to give a somewhat similar aspect. The delineation of HRU's may be based simply on soil characteristics if that is the physical variable which is most significant to the flow of water through the basin (Salisbury 1992). In other cases snow melt may be the most important factor in the production of runoff, which would make the elevation, slope, and aspect characteristics of the basin very important to basin delineation, as they have a strong influence on the timing and movement of snow melt (Leavesley and others 1983). 
The physiographic method is a complex process, which can lead to a very complex and large set of HRU's that need not be contiguous areas. The basis for HRU delineation can be the systematic subdivision of the basin into a set of grid squares that are based only on a set of proximity constraints (Leavesley and others 1992a), and have no basis in its physical characteristics. The systematic grid method is very simple and is constrained to produce only contiguous areas.

Integrated. This approach, which is a combination of the first two methods, is still in the development stage, but shows promise. If successful, the current studies will provide much more detailed physical descriptions of basins for input to models at lower costs and in shorter times. For example, at the USGS Water Resources Division (WRD) Offices in Carson City, Nevada, a team of scientists has produced a prototype set of HRU's by first automatically classifying the grid cell data which included elevation, slope, aspect, land cover, soils, and geology. They viewed these HRU's and analyzed the statistics to eliminate extraneous HRU's, and combined some of them to produce a set of fifty HRU's for portions of the Carson and American River Basins in Nevada and California (Jeton and Smith 1992, 1993; Smith and Reece 1992). The researchers agreed on fifty HRU's because it was the maximum number of HRU's allowed by the version of the model available to them at the time of the research. It was also selected because it would retain details of the physical characteristics of the basin while not providing more detail than the model could process. This technique produces HRU's that more closely adhere to their original definition, while potentially producing noncontiguous HRU's, which are not acceptable for all applications. Noncontiguous HRU's cannot be used in the flow routing module as easily as those which are contiguous, but can be used in applications such as the one used in this study (PRMS). The PRMS model is used primarily to model small upland basins, which are later combined using the flow routing module to produce runoff information for the larger basins.

Several other projects are in progress using GIS techniques to determine the boundaries of HRU's. A group of scientists at both the University of Oklahoma and Oklahoma State is studying various aspects of modeling a small portion of the Little Washita Basin in south central Oklahoma using a model developed by the Agricultural Research Service (Williams 1992). Starting with a resolution of 30 meters in their GIS data base, they are attempting to incorporate next generation weather radar (NEXRAD) data into surface water modeling (Nicks and Schiebe 1992). One of the studies is concerned with the effect of spatial and temporal variability of precipitation on model results (Williams, 1992). Another is looking at the effect of spatial aggregation of HRU-like areas on model results to assess the effect of HRU size on model results (Salisbury, 1992).

A study on the automated generation and generalization of soil-based HRU's has also been done (Salisbury 1992). In this study, it was found that the reduction of the number of soil-based subareas into which the basin was divided had little effect on model results until the number of subareas was reduced from 102 to 4 . A study of annual response found that annual evapotranspiration projections did not change significantly with decreasing number of HRU's until the number was very small, but the scientists intend to study the same range of HRU sizes over smaller time periods to see if the same result occurs (Williams 1992). One of the first publications to come out of this study describes the use of Landsat imagery to 
subdivide the basin into "areas of homogeneous vegetation" to replace the use of subbasins to derive hydrologic response information (Duchon and others 1992).

The Bureau of Reclamation [in Salt Lake City] has generated a set of HRU's for the Gunnison River Basin using the integrated method with vector data instead of the more popular raster image processing techniques (Ryan 1992). Several studies have demonstrated the ease of deriving large numbers of basin characteristics from GIS and remote sensing tools (Eash 1993; Martz and Garbrecht 1993; Garbrecht and Martz 1993; Chairat and Delleur 1993; and Luker and others 1993).

The automated and integrated methods for deriving HRU boundaries are growing in number, but the use of HRU's or similar subdivisions of basins for modeling has been a common practice among hydrologists for many years. One reference goes back to 1969 for agricultural areas (England and Holtan 1969). Not all works use the label "HRU", but they each try to represent spatial variation in a study area by a similar process. In fact, the other hydrologic model used by USGS personnel with regularity, Hydrologic Simulation Program - Fortran (HSPF) also uses similar types of units to subdivide the basin into segments (Bicknell and others 1992).

In a study of a treated rangeland watershed, Osborn and Simanton (1990) subdivided a basin into overland flow areas and calculated surface geometry based on each of them. Stephenson and England (1969) used soils, topography, and land cover to develop soil mapping units to reduce computational complexity and increase efficiency in design of hydrologic experiments. England and Holtan (1969) derived HRU's based on soil, slope, vegetation, microclimate, and land use for a small agricultural watershed (Holtan 1969), and England (1970) proposed a soil grouping based on hydrologic response.

Although, basin size and type were different in his model, Thomas (1990) used overland flow segments (OFS), which are similar to HRU's, to calibrate the distributed routing rainfall-runoff model (DR3M) to study a small watershed in New Mexico.

Wood (1987) attempted to determine an optimum representative elementary area (REA) number and size (an area similar to an HRU) to subdivide study basins, by studying the effect of changing the size and number of the REA's on the model results. In addition, similar techniques are being used at the Bureau of Land Management (BLM) to delineate more generalized biophysical land units (BLU) that represent areas of common response to the physical processes which they are studying (Carroll 1992). Still others wish to define "hydrologically homogeneous regions" based on canonical correlations of both physical and hydrologic characteristics of basins, to aid in the application of predicted response from gaged to ungaged basins (Cavadias 1990).

\section{The Role of DEM's in Hydrologic Modeling}

A major source of input for hydrologic models is elevation data (USGS 1990). The availability of digital elevation data for part of the nation at a resolution of 30 meters (for small area studies), and for all of the nation at a 3 arc- 
second sampling size (for regional studies) has been a major catalyst in the incorporation of digital elevation information in the modeling process. In addition, the ability of GIS to quickly calculate slope and aspect, and delineate basins, subbasins, and stream networks has enhanced the ability of hydrologic models to represent the physical processes at work in basins. Powerful terrain modeling tools allow the modeler to quickly determine direction of flow and flow accumulation throughout the basin (Jenson and Domingue 1988; Moore and others 1991; Pick 1987). However, these capabilities can be both an aid and a detriment depending on their use. If used properly with good data, research can be advanced, but if the tools are improperly used, valuable resources are wasted. As GIS-hydrologic model linkages continue to develop (Leavesley and others 1992b; Ryan 1992; Gunderson 1992; Eash 1993; Martz and Garbrecht 1993; Garbrecht and Martz 1993; Chairat and Delleur 1993; and Luker and others 1993), studies are beginning to address resolution issues (Pilotti and Rosso 1990; Battaglin and others 1993; Chairat and Delleur 1993). However, the literature is still limited regarding the impact of this particular aspect of research.

Recent research has examined the effect of resolution on runoff (Fellows and Ragan 1986; Mancini and Rosso 1989; Wolock and Price 1992). Fellows and Ragan (1986) looked at very small basins using $1: 24,000$ scale data which was generalized from 30 meters to 300 meters to assess the effects on a Soil Conservation Service (SCS) model. They studied error in basin delineation and parameter calculation based on cell size using an SCS hydrologic model (SCS-TR-55) commonly used for basins of 327 hectares ( 809 acres) or less. The research included 237 basins ranging from 0.13 to $44 \mathrm{~km}^{2}$ and 5 cell sizes $(30,60,120,210,300 \mathrm{~m})$. The basins were delineated at each of the resolutions, thereby changing the size of the area to be modeled and the area on which the other parameters were calculated before peak flow data were generated. The analysis concluded that the model parameters were relatively insensitive to changes in cell size of land cover and soils data, although they were sensitive to changes in the cell size of the elevation data because of the model's use of runoff timing factors.

In a second study, Mancini and Rosso (1989) also looked at the influence of cell size on runoff. Intensity of rainfall and physical basin parameters were applied to the SCS runoff curve number (based on land cover and soil type) to calculate runoff. They found that curve number varied with spatial scale and that the statistical distribution of the curve number was related to the local drainage pattern. In the third study, TOPMODEL was applied to the Delaware River Basin to compare 1:24,000- and 1:250,000-scale DEM's. Researchers found that the 1:24,000-scale data provided better model calibration (Wolock and Price 1992).

In each of these studies, the issue of spatial resolution was addressed on one level or another, but none of them isolated the effect of the input data resolution on predicted response. They either compared data from different sources, or varied several parameters, or changed the area on which the runoff was being modeled by redefining the boundary of the basin.

With the availability of highly detailed elevation data, and models capable of handling large data sets, it has become more important that the models be tested for the appropriate resolution of DEM data. Anything greater than an appropriate resolution would be wasteful and use more time and resources to process. Anything 
less would not serve the model well. As elevation data at varying resolutions become more available, the selection of a proper resolution becomes more critical.

\section{Grid Cell - Raster Data}

The development of digital spatial data began with grid cell data. (The terms raster and grid cell will be used interchangeably.) Maps were first computerized by recording map values at regularly spaced intervals to create matrices for use in manipulation and statistical analysis software. During the 1960's, the displays of maps from the computer were extremely coarse, due to the size of the sampling intervals and the use of line printers as display devices (Coppock and Rhind 1991). The distortions caused by the rectangular shape of the line printer symbols could be minimized by the use of a rectangular sampling pattern, but there was little acceptance of such printouts as publication quality products. In fact, there was little concern about the quality of the line printer maps, because the information generated by the computer was the important part, and most graphics for presentation or publication were still manually drawn and lettered (Coppock and Rhind 1991). Increasing availabilityof computers, in part, led to the quantitative revolution in geography (Sinton 1992). At the same time, work continued on automated cartography, which had as its goal to draw the very same maps using the computer instead of using manual techniques (Robinson and others 1984). Work at Harvard University in the 1960's and 1970's produced SYMAP and GRID, and led to the development of ODYSSEY, ERDAS, Intergraph, and ESRI software systems by the large number of researchers who had worked there during the 1960's (Chrisman 1988). Those activities, combined with the development of scanner and plotter technology, led to increased speed of encoding and plotting of data in Canada (i.e. Environment Canada), which further advanced the cause of digital data base development in both grid and polygon formats (Sinton 1992).

In the 1970's the research community continued to develop the hardware and software (especially digitizer and scanner technology) to input, manipulate, and output map information in vector form. When the resolution at which data were recorded was sufficient, the pen-plotted images generated from the vector data were more widely accepted for use in publications than had previously been the case.

These vector data structures, which appeared to more accurately represent the original maps, were preferred over raster data for analytical purposes as well (Goodchild and Gopal 1989). Vector data required much more complex algorithms to support manipulation and analysis functions. In most cases the storage required for maps of equivalent size was much less if maintained in vector format, but the complex algorithms required to perform vector analyses developed more slowly than those required for grid analyses.

The continued development of automated digitizing equipment in both the raster and vector arenas, the speed of the raster scanners, and the development of programs to convert scanned data to vector data, when combined with the very high resolution of the scanners and raster plotters, again raised the raster-versus-vector question, which had been debated when vector data bases were first developed (Sinton 1992). If the data were first recorded in raster form, what was the benefit 
of vectorizing them? In addition, the increasing availability of satellite imagery (which is in raster format) increased the need for raster processing software and directed research dollars toward that development.

The growing interest in combining remotely sensed raster imagery with digital data of other types has forced some GIS vendors to address the need for both raster and vector based analysis software and conversion packages so that the data formats may be interchanged as needed. In some cases the vendors developed programs to reformat the data from other systems for use in their own systems and vice versa; others developed strong ties with vendors who met the needs of the other half of the user community; and still others have attempted to develop systems with full raster and vector capabilities (GIS World 1992).

It is now widely accepted by software developers and users of digital spatial data that both raster and vector data bases have value, and each can be preferable to the other depending on the requirements of the activity. Representations of linear features (e.g. the center line of a pipeline) and distinct boundaries (e.g. political boundaries) are applications for which the vector form of data is preferable, while maps that contain information which is continuous or transitional in nature are better represented as raster data (Maffini 1987).

Perhaps the history of raster and vector data is best illustrated by Sinton's description of his involvement in the development of Geographic Information Systems over the past twenty years:

Twenty years ago, I ardently espoused thematic grid models as the solution to all our problems. Ten years ago, I sold "spaghetti" vectors. Today, I am working on the integration of interactive topological vectors with remotely sensed raster data. If I have learned anything over the last 25 years, it is that no one data model is suitable or cost effective for all applications. More importantly, I have learned that all the different data models have a role in a complete GIS (Sinton 1992).

\section{Digital Elevation Model Data}

Digital elevation model (DEM) data development can be traced as far back as the late 1950's. They were referred to as digital terrain models which were described as "information systems that store, manipulate and display information about terrain" (Peucker 1979). As with the development of digital data in general, there have been discussions of regular and irregular sampling, the type of elements to use in the data base, and the type of DTM data structure that is preferable (Peucker 1979):

1. point structures and networks (rectangular grids),

2. line structures (contours or profiles), or

3. patch structures (mathematical functions).

In the more recent literature, the term "DTM" has been used to refer to the elevation data alone: "A DTM may be understood as a digital representation of a portion of the earth's surface" (Weibel and Heller 1991) and the application 
software referred to as application-specific systems. Burrough (1986) made the case that "DEM" should be used instead of "DTM" when speaking of elevation data alone.

Currently, the two most popular elevation model structures used for terrain analysis are the rectangular grid and the triangulated irregular network (TIN) (Weibel and Heller 1991). But most research begins with data in the rectangular grid format because it is the structure used by the Defense Mapping Agency (DMA) and the U.S. Geological Survey (USGS), the agencies with the most active digital elevation data collection programs. The DMA has produced complete DEM coverage (in meters) of the conterminous United States at a resolution of 3 arc seconds. It is referenced horizontally on the geographic (latitude and longitude) coordinate system of the World Geodetic System 1972 Datum (WGS 72) or the World Geodetic System of 1984 (WGS 84) with each file covering a 1 x 1 degree block. The data were originally generated from 1:250,000-scale topographic maps and turned over to the USGS for dissemination through its network of map and data sales offices. The DMA produces other elevation data bases, but the distribution of those data sets has been more selective. The USGS produces most of its DEM data [at a resolution of 30 meters, sampled] on a 30-meter grid in the Universal Transverse Mercator (UTM) coordinate system. The reference datum may be North American Datum of 1927 (NAD 27) or North American Datum of 1983 (NAD 83) for the conterminous states. The unit of coverage is the 7.5-minute, 1:24,000-scale quadrangle. Although the USGS also produces other types of DEM's, their coverage is limited and not relevant to this research (USGS 1990).

In an evaluation of the utilization of DTM's, Yoeli (1983) lists several limitations to data collected in the 3-arc-second DEM's. He warns that any data collected at a regular interval are likely to miss the most significant points (e.g. minimums and maximums), because they are limited by the "methodology of the computer software applied." "DTM's created by the interpolation of heights between contours are of a secondary character and their quality depends on the accuracy of the contours" among other elements. In addition, he states that, "The accuracy of the information about the earth's relief as contained in cartographic contour depictions is frequently highly overestimated!" (Yoeli 1983). Despite such concerns, the research community has continued to utilize the DMA DEM's at an increasing rate because there is no other nationwide source for similar information. This is also the case in the modeling community: the scientists must use the information available. Because of the widespread use of the 3-arc-second DEM's, they were selected for this research, while realizing that they are not error free nor without significant flaws. They are, in fact, the highest resolution elevation data available with complete coverage of the study site.

\section{Generalization}

Studies of techniques for the generalization of grid cell data have been going on since the first cells were generated. One of the earliest works on the subject is by Tobler (1966), in which he defined map generalization as the "application of a transformation which modifies the map data". He discussed the techniques that 
could be used to generalize topographic maps, the need for the preservation of statistical parameters (e.g. mean and standard deviation) through the process of generalization, and the importance of the process being reversible. He discussed the use of trend analysis, moving averages, and spatial frequency filters such as Fourier analysis (Tobler 1966). In the remote sensing community, the first studies began shortly after receipt of the initial data from satellite platforms (Moellering and Tobler 1972).

Generalization has continued to receive attention over time. Although computer storage and processing capacities and speeds have increased by orders of magnitude, so have the sizes of the data bases being collected and processed (Wiggins and others 1992). Interest has also heightened because of the increase in research which requires global data bases (Tobler 1988; Kelmelis and Watts 1991; Mounsey and Tomlinson 1988). According to Muller (1991), there are two types of generalization: cartographic and statistical. While cartographic generalization is primarily concerned with visualization (Buttenfield and McMaster 1991; Catts 1990), statistical generalization is concerned more with attribute data (Muller 1991). This research will address the latter - specifically the effects of increasing the sample interval or cell size (decreasing resolution), which usually implies decreasing accuracy (Goodchild 1980; Goodchild 1989; DeCola 1991; Weibel and Heller 1991).

There is a difference between resolution and accuracy, although many people would use the two terms interchangeably. According to the Spatial Data Transfer Standard (SDTS), accuracy is "the closeness of results of observations, computations or estimates to the true values or the values accepted as being true" (USGS 1992). Resolution is the "minimum difference between two independently measured or computed values which can be distinguished by the measurement or analytical method being considered or used" (USGS 1992) or "the capability of making distinguishable the individual parts of an object" (Tobler 1988). The appropriate scale (resolution) of representation differs according to the phenomena being represented. For example, the various time scales at which climate models may be run will highlight different types of weather and climatic patterns. Therefore, a model run on annual data will do little to predict daily weather patterns, and a model run on hourly data will do little to demonstrate patterns of climate change. Neither level of temporal data resolution is better than the other, but is simply suited for different use (Eagleson 1985), and its accuracy is determined only by its comparison within the context of the specific application. Regardless of the resolution of a data base, its accuracy is also determined by the quality of the process used to create it (Eagleson 1985; MacEachren 1987; Theobold 1989).

Once an application has been selected, the resolution of the data used in the analysis becomes more critical and is more closely associated with the accuracy of the information, because only then can it be compared with reality at the selected resolution. Nevertheless, the choice of cell size is also a function of at least two other factors: time and cost (Bregt and others 1991).

Some studies concerned with differing resolution in the DEM's have dealt with the comparison of data bases of different resolutions (Acevedo 1991; Carter 1989; Wolock and Price 1992; Jones 1990). These studies address the comparison of data from the USGS $1: 24,000$ - or 1:100,000-scale data base with that from the DMA 1:250,000-scale data base. Acevedo (1991) compared the data compiled at 
1:100,000-scale to that published at $1: 250,000$ and found significant differences between them, some of which were a result of compilation techniques. Another study of USGS DEM's evaluated the relative accuracy in 1:24,000 and 1:250,000scale files (Carter 1989). The third study above compared hydrologic model results produced from the use of physical parameters based on the 1:24,000-scale DEM's with those from 1:250,000-scale data when predicting flood peaks (Wolock and Price 1992). The fourth study compared the performance of 1:24,000 and 1:250,000scale elevation data in the calculation of parameters for a variety of basin sizes and shapes, and found significant differences between the two scales (Jones 1990). Battaglin and others (1993) varied sample intervals of elevation and estimated precipitation from 2.5 to 10 kilometers and noted changes in the prediction of hydrologic response for a portion of the Gunnison Basin in Colorado. Chairat and Delleur (1993) varied grid cell resolution from 30 to 90 meters to assess the effect on runoff predictions.

The comparisons have been extremely interesting and helpful to the users who must choose among the data bases, but most comparisons are not simply based on differing resolution. The differences between the data bases are also the result of several other factors: different equipment, source material, sampling techniques and operators (MacEachren 1987). Thus, it becomes very difficult to distinguish whether the differences between the elevations are simply from the data resolution, or from the other factors involved in the creation of the data bases.

This research has excluded many of the other issues which were a part of previous studies by using only one source of elevation data throughout the research and by providing the varying resolutions by using one algorithm to generalize the same elevation data - the 3-arc-second digital elevation data. Thus, the differences between the data sets used to generate input for the hydrologic model were solely the product of cell size and the generalization algorithm used in the process: cubic convolution (Jensen 1986). 


\section{METHODOLOGY}

To test the hypothesis that the Precipitation-Runoff Modeling System was sensitive to the generalization of the elevation data it was necessary to analyze the effect of generalization on the elevation data at the basin and HRU level and then assess its effect on model output from the varying resolutions. Once the study site was selected, the paired-difference t-test was used to evaluate basin and HRU parameters, and regression analysis was used to study the relationship of other physical characteristics on the changes in slope due to generalization. The hydrologic model was then used generate runoff based on 100 and 1000 meter data. Model results were compared using the paired-difference $t$-test to determine the significance of the changes in runoff produced by generalization. Throughout the analysis, the parameters and predictions based on the 100 meter data were used as the control set to which the other predictions were compared.

\section{Study Site}

The basin used in this study was the East River drainage of the Gunnison River Basin in Colorado shown in figure 1. It is situated just west of the Continental Divide and combines with the Taylor River drainage (on its east) to form the Gunnison River in figure 2. It covers an area of approximately 750 square kilometers (290 square miles); elevations range from 2,433 to 4,272 meters. The basin is ideal for this application of the PRMS type of model because it has no significant reservoir storage and because it is located at the headwaters of the much larger Colorado River Basin.

The existence of an ongoing research project had a strong influence on the selection of the East River basin for this research. The basin is currently under study by a team of hydrologists from the USGS Water Resources Division (WRD) in Denver, Colorado, as part of the USGS Global Change Research Program (Battaglin and others 1993; Hay and others 1992; Kuhn and Parker 1992; Leavesley, Branson, and others 1992; Leavesley, Restrepo, and others 1992). They have developed several parameter sets for PRMS for this basin and have provided their initial HRU boundaries, as well as both the batch and interactive modular versions of the PRMS for use in this study. In addition, runoff and precipitation data were already assembled for the basin by the WRD personnel and had been entered into the data base portion of the interactive version of PRMS.

According to the land use - land cover data, the East River basin is predominantly agricultural and rangeland, with small settlements (e.g. Crested Butte) and farmsteads scattered throughout the lower elevations (USGS 1986). In the upper reaches of the basin, there is substantial alpine tundra, exposed rock, and snow throughout most of the year. With its primary water source being snow melt, it was an ideal basin in which to study the effects of the spatial resolution of slope and aspect on runoff. 


\section{Data Acquisition}

\section{Digital Elevation Data}

The 1:250,000-scale 3-arc-second-resolution DEM's were retrieved from the USGS data archive (USGS 1990). This data base was selected for the research because it was the highest resolution digital elevation data base currently available for the study area. It is the highest resolution elevation data set with full coverage for the conterminous United States. As a result, it is used in many of the research projects that require the use of elevation data. It was produced by the Defense Mapping Agency and was subsequently delivered to the USGS for distribution through its nationwide network of map and data sales offices. It was derived from 1:250,000-scale topographic map coverage by digitizing the contour lines with a contour interval of 100 to 200 feet.

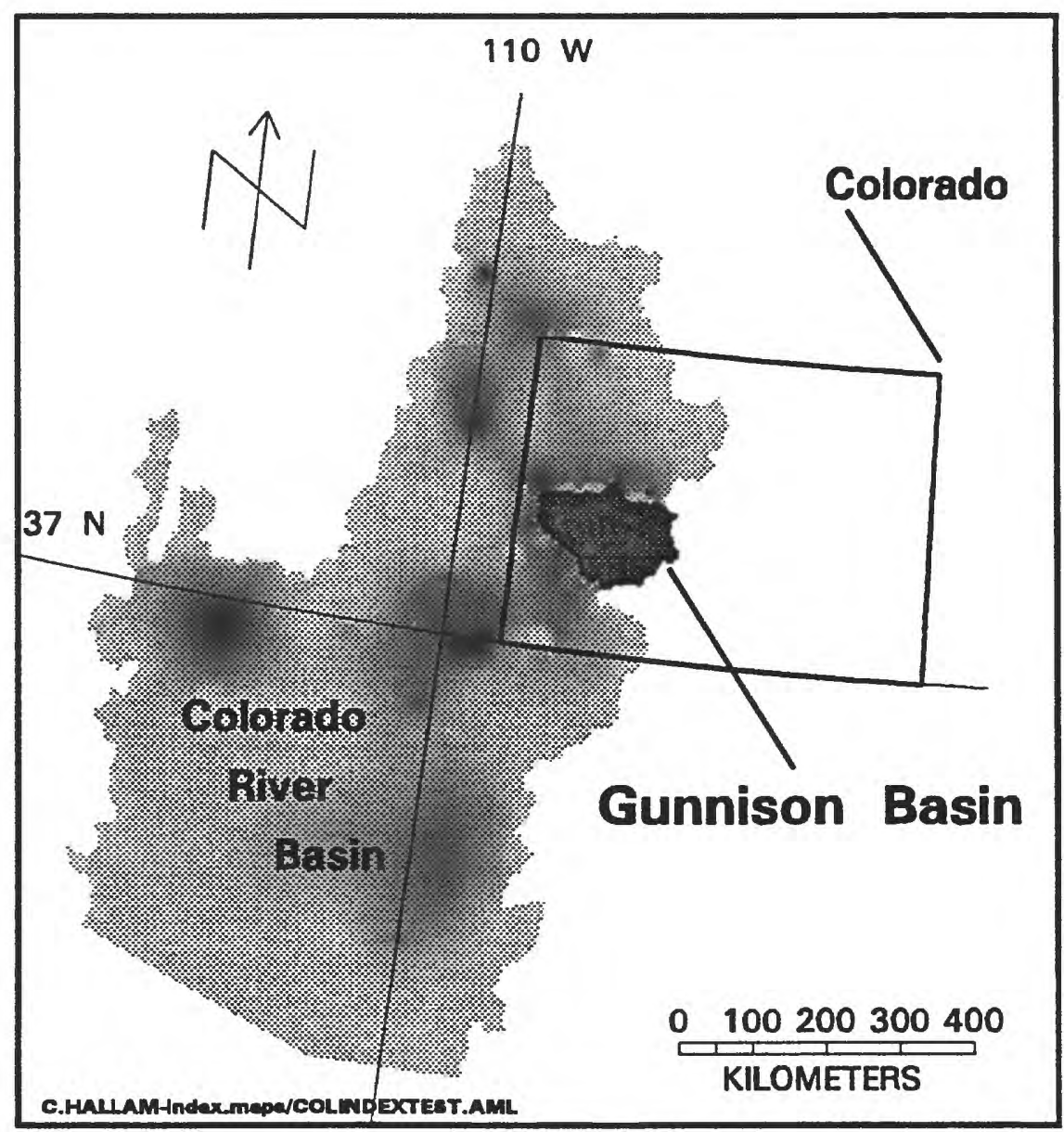

Figure 1. Gunnison River Basin location map. 


\section{Basin Discharge}

Daily runoff information for the East River is measured at the stream gage in Almont, CO. These data were received from the Water Resources Division (WRD) of USGS in Denver, CO, already formatted for use in the hydrologic model.

\section{Precipitation Data}

Daily precipitation information was extrapolated for the HRU's by the scientists in WRD in Denver, CO using an orographic model, which estimated total precipitation for each $5 \mathrm{~km}$ by $5 \mathrm{~km}$ cell within the basin based on information from the climate station at Crested Butte (Hay and others 1992).

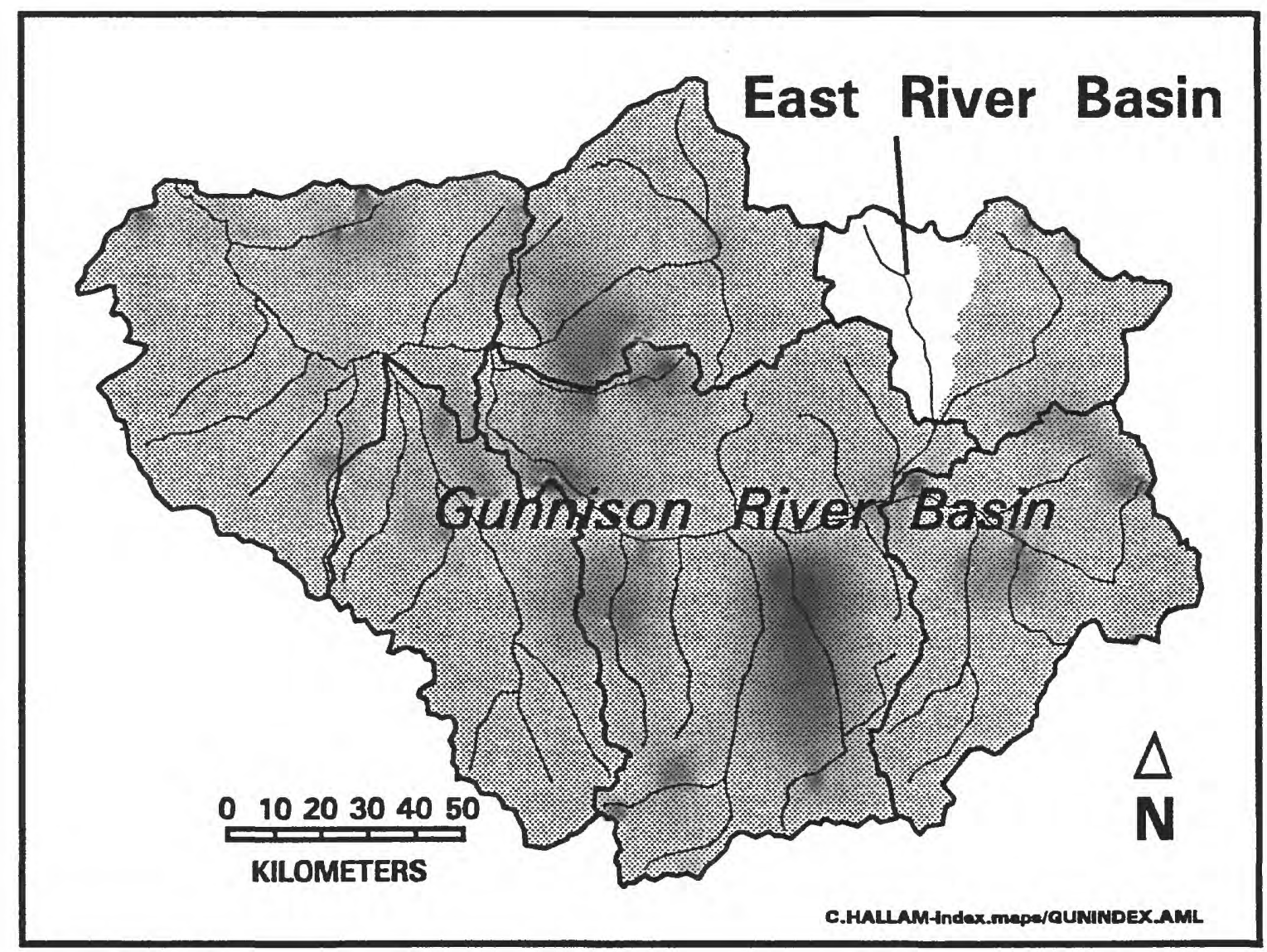

Figure 2. East River Basin location map. 
HRU Boundaries

Boundary files for the HRU's were also received from WRD (figure 3). They were delineated on 1:24,000-scale topographic maps using the manual method based on topographic, land cover, geologic and soils maps (Kuhn and Parker 1992). They were then digitized and edited to produce a vector data set (Battaglin and others 1992).

As originally delineated, the basin contained 50 HRU's (polygons), but for the two previous WRD studies in which the basin was examined, the HRU's were combined into 17 HRU's (Leavesley, Branson, and others 1992) or 14 HRU classes (Kuhn and Parker 1992), which were not all contiguous areas but were in close proximity. For this research, the set of 17 HRU's developed by Leavesley was used. The elevation-related parameters were generated directly from the HRU and elevation files. The other HRU parameters were used as they were compiled by Leavesley for his study of the 17 HRU's.

\section{Data Preprocessing}

The DEM data were acquired as one-degree by one-degree blocks and merged to produce a file of complete 3-arc-second cell coverage for an area that fully contained the basin. The elevation file was then resampled to a 100 meter UTM grid. The decision to use the 100 meter cell size was made based on the size, in meters, of 3 arc seconds at the latitude of the study site. The basin falls between 38 and 40 degrees north latitude, where 3 arc-seconds represents approximately 95 meters north-south. To best replicate this sampling size, without implying an increase in spatial resolution, a cell size of 100 by 100 meters was selected for the initial elevation data set. The data set was then transferred to the GIS in which the analysis was performed, and the elevation file was generalized using the same origin with larger cell sizes $(200, \ldots, 900,1000$ meters). Cubic convolution techniques (Jensen 1986) were used to generalize the data to minimize the information loss.

The DEM data at each resolution were used to produce slope and aspect layers for each basin representation. Slope, aspect, and elevation files were then resampled to the 100 meter cell size using nearest neighbor techniques to prevent any changes in the level of detail in the data.

The HRU boundaries were gridded to the same 100 meter cell size and origin as the elevation data, however, to avoid changing the shape or size of the HRU's or the basin itself the HRU's were not resampled to the larger cell sizes. The analysis was performed at the 100 meter grid cell size (maintaining the original boundaries of the HRU's throughout the research) to avoid the modifiable area unit problem, which could have invalidated the use of standard statistical techniques (Openshaw 1984). 


\section{Hydrologic Response Units}

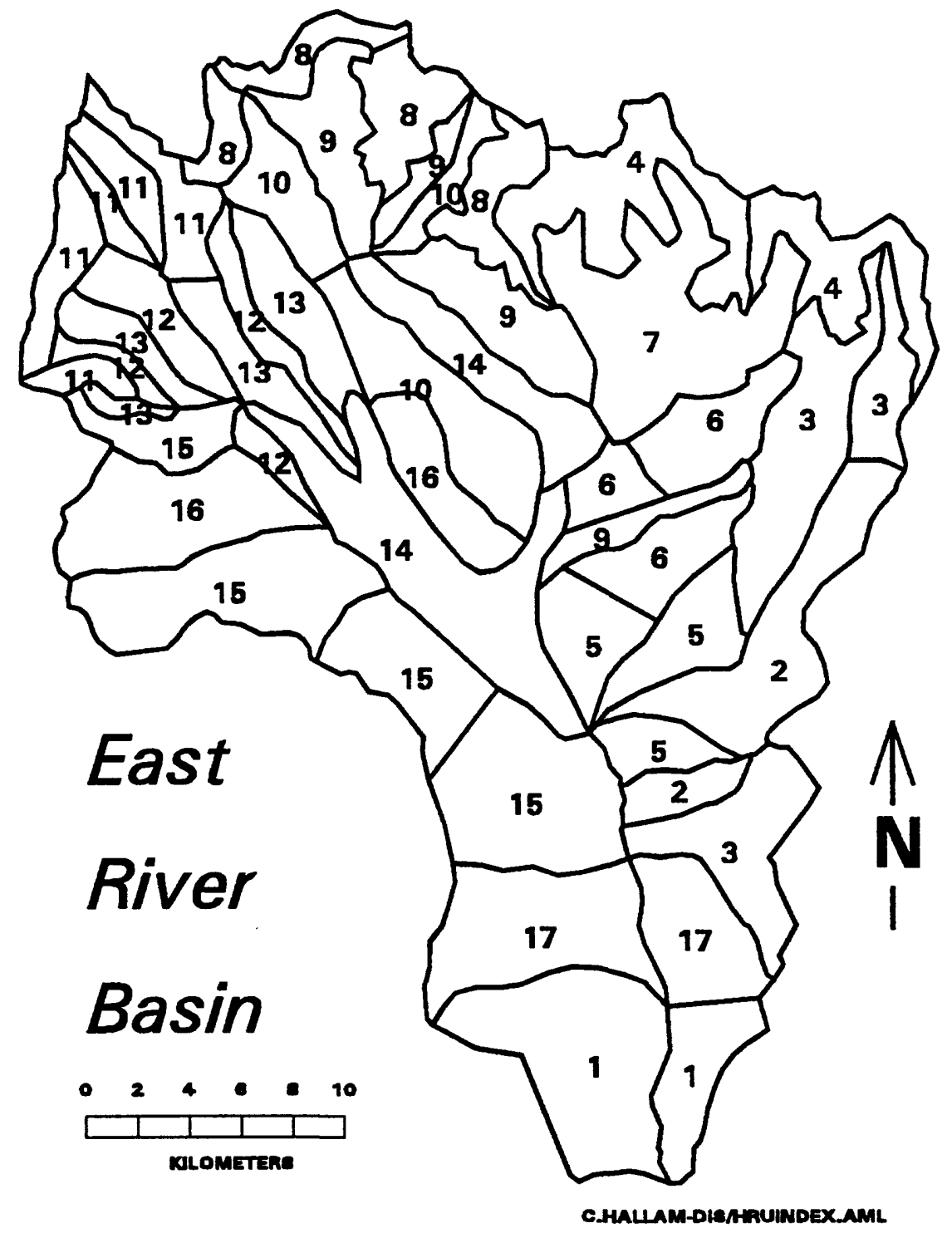

Figure 3. HRU boundaries for the East River Basin. 


\section{Generation of Topographic Statistics}

\section{Calculation of Basin Statistics}

Statistical descriptions of the basin were generated for elevation and slope at each resolution using the GIS. In addition, correlations were produced for the elevation, slope, and aspect of the basin at each resolution. The aspect correlations were calculated based on the cosine function of the aspect for each cell, to best portray its cyclic nature. Elevation, slope, and aspect frequency histograms were graphed to display the effect of decreasing resolution on them. Elevation, slope, and aspect correlations were plotted to show the declining correlation with data generalization.

\section{Calculation of HRU Statistics}

Mean elevation and slope were calculated for each HRU at each resolution using a grid technique. This permitted the use of the gridded HRU boundaries as a set of zones within which the mean was calculated based on the information contained in the second grid (elevation or slope).

Aspect was estimated for each HRU at each resolution by assigning the raw aspect to nine classes (the eight compass directions and a class for flat areas). The aspect zones were then combined with the HRU boundary grid to calculate the percent of each HRU occupied by each aspect zone. Table 1 contains the split of three of the HRU's using the 100 meter data. The model is equipped to use an aspect of any degree, but for the purposes of this research a generalized aspect was generated for each HRU. Because the model does not differentiate in its calculations between east and west, northwest and northeast, or southwest and southeast, and because there were no completely flat HRU's, the zones were combined into five classes, N, NE/NW, E/W, SE/SW, and S, and assigned values of $0^{\circ}, 45^{\circ}, 90^{\circ}, 135^{\circ}$, and $180^{\circ}$, respectively. The aspect covering the greatest percent of the HRU was selected as the representative aspect, but because the aspect with the largest percent area seldom covered the majority of the HRU, a second step was used. To account for the effect of other significant classes, the dominant aspect was averaged with its largest neighboring aspect if the percent area of that aspect minus the percent area of the other neighboring aspect was greater than or equal to one half the percent area of the dominant aspect. For example, if the direction occupying the largest percent of an HRU faces $\mathrm{E} / \mathrm{W}$, it becomes the dominant aspect. Then, NE/NW and SE/SW percentages are used to determine whether a shift to the North or South from the E/W direction should be made. That decision is based on two criteria:

1. If $(\mathrm{NE} / \mathrm{NW} \%)-(\mathrm{SE} / \mathrm{SW} \%)<(\mathrm{E} / \mathrm{W} \%) / 2$, then the aspect $=\mathrm{E} / \mathrm{W}\left[90^{\circ}\right.$ or $\left.270^{\circ}\right]$

2.a) If $(\mathrm{NE} / \mathrm{NW} \%)>(\mathrm{SE} / \mathrm{SW} \%)$, then aspect $=\mathrm{ENE} / \mathrm{WNW}\left[67.5^{\circ}\right]$

b) If $(\mathrm{SE} / \mathrm{SW} \%)>(\mathrm{NE} / \mathrm{NW} \%)$, then aspect $=\mathrm{ESE} / \mathrm{WSW}\left[112.5^{\circ}\right]$ 
Table 1. Sample listing of aspect zone assignments.

\begin{tabular}{|c|c|c|}
\hline HRU & $\begin{array}{c}\text { PERCENT } \\
\text { COVERAGE }\end{array}$ & DIRECTION \\
\hline \multirow{8}{*}{1} & 10 & $\mathbf{N}$ \\
\hline & 21 & $\mathrm{NE}$ \\
\hline & 26 & E \\
\hline & 8 & SE \\
\hline & 2 & $S$ \\
\hline & 4 & SW \\
\hline & 12 & $\mathrm{~W}$ \\
\hline & 13 & NW \\
\hline \multirow{8}{*}{2} & 15 & $\mathrm{~N}$ \\
\hline & 7 & $\mathrm{NE}$ \\
\hline & 1 & E \\
\hline & 0 & SE \\
\hline & 1 & $\mathrm{~S}$ \\
\hline & 8 & SW \\
\hline & 28 & W \\
\hline & 36 & NW \\
\hline \multirow{8}{*}{17} & 1 & $\mathrm{~N}$ \\
\hline & 3 & $\mathrm{NE}$ \\
\hline & 15 & $\mathrm{E}$ \\
\hline & 27 & SE \\
\hline & 23 & $\mathrm{~S}$ \\
\hline & 20 & SW \\
\hline & 7 & W \\
\hline & 2 & NW \\
\hline
\end{tabular}


The mean elevation and the slope of each HRU were plotted against resolution as it decreased from 100 to 1000 meters. Histograms were generated showing slope and aspect frequency distributions using the 100 meter data set. To demonstrate the effect of generalization on the distribution of slope for the HRU's, histograms were generated for three of the HRU's at each resolution. HRU 4 represents a high elevation and high slope HRU; HRU 1 represents a low elevation HRU; and HRU 14 represents a low slope HRU. Paired-difference t-tests were performed on the 100 and 1000 meter slope and aspect data to assess the significance of the changes resulting from the decrease in resolution by testing the following hypotheses about the basin data:

and

$$
H_{0}: \text { Slope }_{100}=\text { Slope }_{1000} \text { versus } H_{1}: \text { Slope }_{100} \neq \text { Slope }_{1000}
$$

$$
\mathrm{H}_{0}: \text { Aspect }_{100}=\text { Aspect }_{1000} \text { versus } \mathrm{H}_{1}: \text { Aspect }_{100} \neq \text { Aspect }_{1000}
$$

To account for the spatial variation in the slope difference, the following regression was run:

$$
\text { Slope difference }=\mathrm{f}(\text { mean slope, } \text { HRU relief })
$$

Prediction of hydrologic response

PRMS was run for water years 1973 through 1989 (WY73-WY89) which cover the period from October 1972 through September 1989. The model was run for the entire series of water years to allow evaluation of the runoff statistics for the full period of record. The first run used the 100 meter data to produce total daily runoff (inches) for the basin, which were summed to monthly and annual runoff totals for the analysis. The model was then run with the elevation-based parameters generated from the 1000 meter resolution data set to produce a similar set of output totals for the model. The other parameters were held constant in the 1000 meter run to assure that the changes in output totals were from elevation changes alone.

Comparison of model results

Annual and monthly runoff totals for the basin were used to detect any significant changes in predicted runoff due to changes in the elevation-based input parameters. To assess the effect of the data generalization the following steps were taken:

1. Hydrographs for 100 meter predictions and 1000 meter predictions were generated for a visual comparison of the predicted results with observed runoff.

2. Correlations were generated to compare the observed runoff and each of the runoff predictions, as well as the two predictions for the daily, monthly, and annual resolutions. 
3. The predicted runoff from the control ( 100 meter) data was plotted against that from the 1000 meter data for both annual and monthly totals to visually evaluate the differences in the predicted flow. Also, both 100 meter and 1000 meter monthly predicted runoff totals were plotted against the observed flow to see how well the model predicted the hydrologic response for the 17 years.

4. The difference between the two predictions was compared on the basis of both annual and monthly totals. The difference and percent difference was calculated for each time interval and the percent differences were compared to check for any temporal influence on the differences.

5. The two sets of runoff estimates (100 and 1000 meters) were compared to the observed runoff and to each other using the paired-difference t-test statistic at the annual and monthly level, to test the following hypotheses about the runoff:
$\mathrm{H}_{0}$ : Observed $=$ Predicted $_{100}$
$\mathrm{H}_{0}$ : Observed $=$ Predicted $_{1000}$
versus $\mathrm{H}_{1}$ : Observed $\neq$ Predicted $_{100}$
$\mathrm{H}_{0}$ : Predicted $_{100}=$ Predicted $_{1000}$ versus $\mathrm{H}_{1:}$ Predicted $_{100} \neq$ Predicted $_{1000}$ 


\section{RESULTS}

\section{Basin Statistics}

The first step in the analysis was to look at the effect of generalization on the basin as a whole, as described by the statistics based on the individual cells. Table 2, which lists minimum, maximum, and mean basin elevation for each resolution, shows that data generalization had little effect on mean basin elevation. The mean elevation varied by no more that two meters throughout the generalization process. In fact, it returned to the original value of 3123 meters by the time the cell size reached 1000 meters despite the reduction of the number of cells by nearly 70 percent. The minimum elevation was similarly unaffected by the decrease in resolution with a variation of no more than 8 meters throughout, but the maximum elevation of the basin decreased by nearly 150 meters due to the decrease in resolution. As shown in table 3, mean and minimum slope values were similarly unaffected by generalization, with a decrease of less than one percent, but the maximum slope decreased from 141 to 83 percent. The change in maximum elevation and slope is an indication of considerable smoothing of the elevation (particularly at the high end) and some loss of the representation of surface roughness, which is expected from the generalization process (Weibel and Heller 1991).

It should also be noted that the path taken by the maximum elevation and slope values as they decrease is not a smooth curve. The change displays an erratic pattern as cell size increases. The erratic pattern seems to be due to the coincidence of the new grid center with the center cell of the 100 ineter grid at the $300,500,700$ and 900 ineter sizes. This coincendence of centers causes the values to be skewed toward the original value of the center cell. Despite this artifact, the overall decline in the maximum elevation and slope for the basin also suggests that the lower resolution (1000 meter) data will not provide as accurate a representation of the surface to be modeled as the higher resolution (100 meter) data.

Cell by cell correlations were calculated for basin elevation, slope, and aspect data to assess the changes in the data by comparing data for each of the resolutions with the control data. As shown in figure 4 and table 4, the correlation of the elevation data sets with the control group was high for all spatial resolutions (ranging from 0.9868 for 200 meter data to 0.9219 for 1000 meter data, showing that the generalization had little effect on the original elevation data. Slope, a derivative parameter, showed much greater variation in correlation and decreased systematically with generalization, ranging from 0.9207 for 200 meter data to 0.2650 for 1000 meter data. 
Table 2. Summary statistics describing East River Basin elevation (meters) at each resolution.

\begin{tabular}{|r|r|r|r|r|r|r||}
\hline $\begin{array}{r}\text { Resolution } \\
\text { (meters) }\end{array}$ & $\begin{array}{r}\text { Rows } \\
\text { (no.) }\end{array}$ & $\begin{array}{r}\text { Columns } \\
\text { (no.) }\end{array}$ & $\begin{array}{r}\text { Cells } \\
\text { (no.) }\end{array}$ & $\begin{array}{r}\text { Mini- } \\
\text { mum }\end{array}$ & $\begin{array}{r}\text { Maxi- } \\
\text { mum }\end{array}$ & Mean \\
\hline 100 & 492 & 416 & 1774 & 2435 & 4214 & 3123 \\
\hline 200 & 246 & 208 & 1519 & 2431 & 4214 & 3123 \\
\hline 300 & 164 & 139 & 1404 & 2437 & 4132 & 3122 \\
\hline 400 & 123 & 104 & 1294 & 2436 & 4154 & 3123 \\
\hline 500 & 98 & 83 & 1121 & 2437 & 4184 & 3123 \\
\hline 600 & 82 & 69 & 972 & 2439 & 4006 & 3123 \\
\hline 700 & 70 & 59 & 838 & 2435 & 3997 & 3121 \\
\hline 800 & 62 & 52 & 721 & 2438 & 4136 & 3123 \\
\hline 900 & 55 & 46 & 609 & 2438 & 3959 & 3122 \\
\hline 1000 & 49 & 42 & 552 & 2437 & 4067 & 3123 \\
\hline
\end{tabular}

Table 3. Summary statistics describing the East River Basin slope (percent) at each resolution.

\begin{tabular}{|r|r|r|r|r|r|r||}
\hline $\begin{array}{r}\text { Resolution } \\
(\text { meters })\end{array}$ & $\begin{array}{r}\text { Rows } \\
\text { (no.) }\end{array}$ & $\begin{array}{r}\text { Columns } \\
\text { (no.) }\end{array}$ & $\begin{array}{r}\text { Cells } \\
\text { (no.) }\end{array}$ & $\begin{array}{r}\text { Mini- } \\
\text { mum }\end{array}$ & $\begin{array}{r}\text { Maxi- } \\
\text { mum }\end{array}$ & Mean \\
\hline 100 & 492 & 416 & 1774 & 0 & 141.3 & 27.16 \\
\hline 200 & 246 & 208 & 1519 & 0 & 140.8 & 27.21 \\
\hline 300 & 164 & 139 & 1404 & 0 & 141.3 & 27.13 \\
\hline 400 & 123 & 104 & 1294 & 0 & 96.1 & 27.46 \\
\hline 500 & 98 & 83 & 1121 & 0 & 130.1 & 27.03 \\
\hline 600 & 82 & 69 & 972 & 0 & 99.8 & 26.94 \\
\hline 700 & 70 & 59 & 838 & 0 & 101.1 & 26.88 \\
\hline 800 & 62 & 52 & 721 & 0 & 96.3 & 26.96 \\
\hline 900 & 55 & 46 & 609 & 0 & 105.3 & 27.56 \\
\hline 1000 & 49 & 42 & 552 & 0 & 83.4 & 26.68 \\
\hline
\end{tabular}


Table 4. Correlations between 100 meter and the other data for the basin.

\begin{tabular}{|r|r|r|r|}
\hline Resolution & Elevation & Slope & Aspect \\
\hline 200 & 0.9986 & 0.9207 & 0.9107 \\
\hline 300 & 0.9926 & 0.7872 & 0.8242 \\
\hline 400 & 0.9839 & 0.6702 & 0.7667 \\
\hline 500 & 0.9903 & 0.6777 & 0.7650 \\
\hline 600 & 0.9747 & 0.5627 & 0.6821 \\
\hline 700 & 0.9554 & 0.4704 & 0.6400 \\
\hline 800 & 0.9529 & 0.4374 & 0.5792 \\
\hline 900 & 0.9527 & 0.3790 & 0.5586 \\
\hline 1000 & 0.9219 & 0.2650 & 0.5052 \\
\hline
\end{tabular}

Aspect, another derivative parameter, which has been evaluated using the cosine function, showed a similar degradation in correlation, ranging from .9107 to .5052 . These findings suggest that the spatial resolution of the data has little effect on the original elevation data for the basin over the 100 to 1000 meter range, but that both derivative parameters (slope and aspect) display a decrease in range and decreased correlations when compared on a cell by cell basis.

\section{East River Basin Correlation}

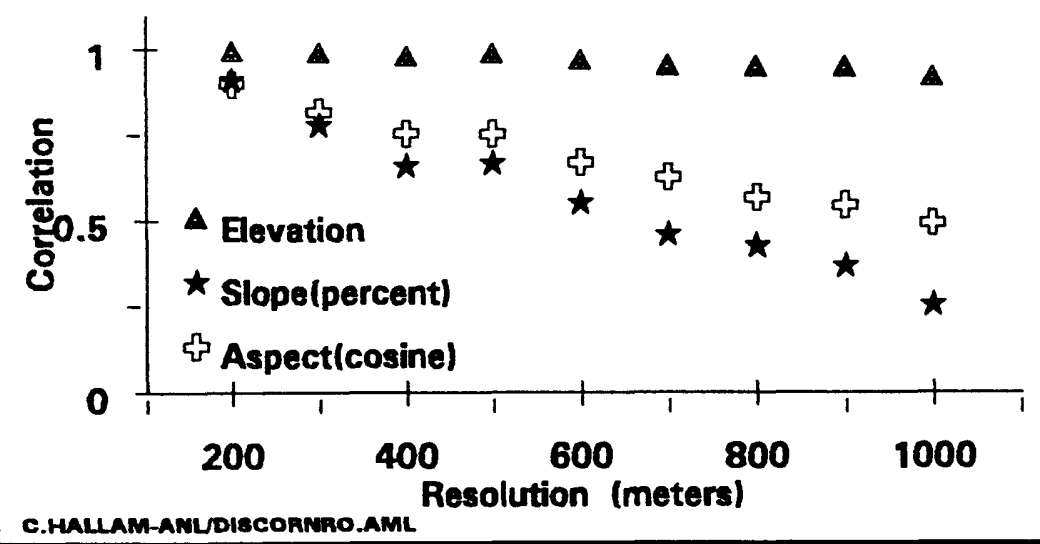

Figure 4. East River Basin correlations with the 100 meter data control group. 


\section{HRU Statistics}

Elevation, slope, and aspect data were estimated for each HRU at the different resolutions, thereby stratifying the elevation data and reducing the variability within each HRU. While this process requires lumping individual cell values into HRU's to produce only one elevation, slope, and aspect for each HRU to represent the basin in the model, it increases the level of representation of diversity within the basin in the modeling process by increasing the number of elevation, slope, and aspect values from one for the basin to 17 - one for each of the 17 HRU's. When compared to the individual cells, the 'homogeneous' areas (HRU's) would then, provide a smaller amount of variability to the generalization process, which might lead to a smaller change in the HRU-to-HRU comparisons compared to the cell to cell comparisons.

Mean elevation displayed no significant resolution-based changes at the HRU level in figure 5, as had been the case in the cell by cell comparisons. Although the plots displayed some changes in the mean elevation of each of the HRU's at each resolution, the changes showed no consistent direction or amount. HRU 4, which had the highest mean elevation, increased in elevation with generalization, as did the second highest HRU (8). HRU 1, which was the lowest in elevation, also increased in elevation by a small amount with generalization, suggesting that mean elevation of an HRU has little to do with the resolution of the data from which it is calculated.

Mean slope showed substantial decreases for most HRU's, with figure 5 showing only HRU 14 (the flattest HRU) to display no decline. Those changes can be understood most easily when the statistical distribution of slope within each HRU is studied using figure 6. A closer look at some sample HRU's also helped to explain the changes. The high elevation, high slope HRU's, such as HRU 4, which is shown in figure 7, demonstrated major changes in the statistical distribution of slope as they were generalized, while the flattest HRU (HRU 14, figure 8) demonstrated the least change. The lowest elevation HRU (1, figure 9) displayed a moderate change in slope distribution after generalization. 


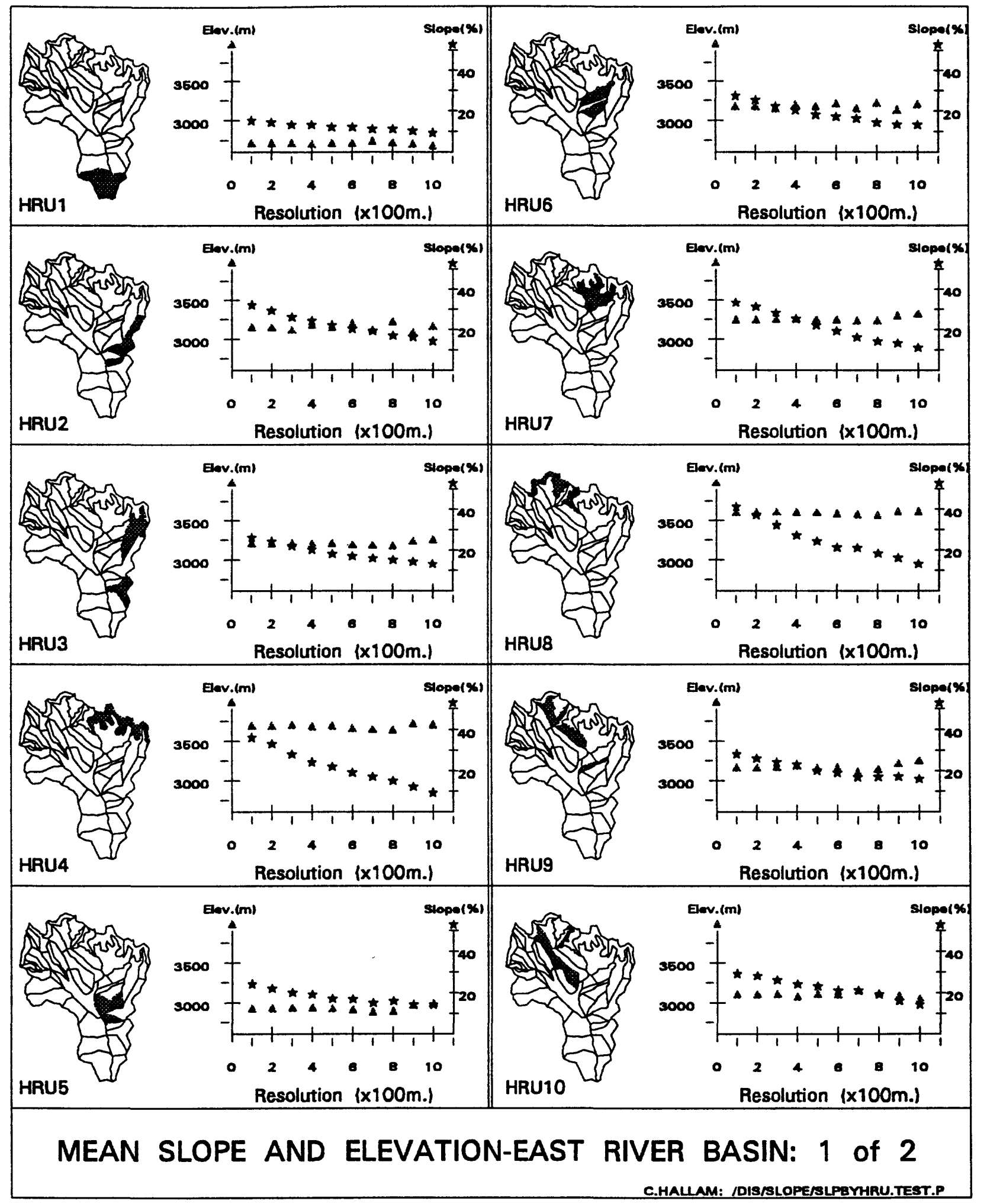

Figure 5a. Plots of mean elevation and slope for HRU's 1-10 in the East River Basin. 


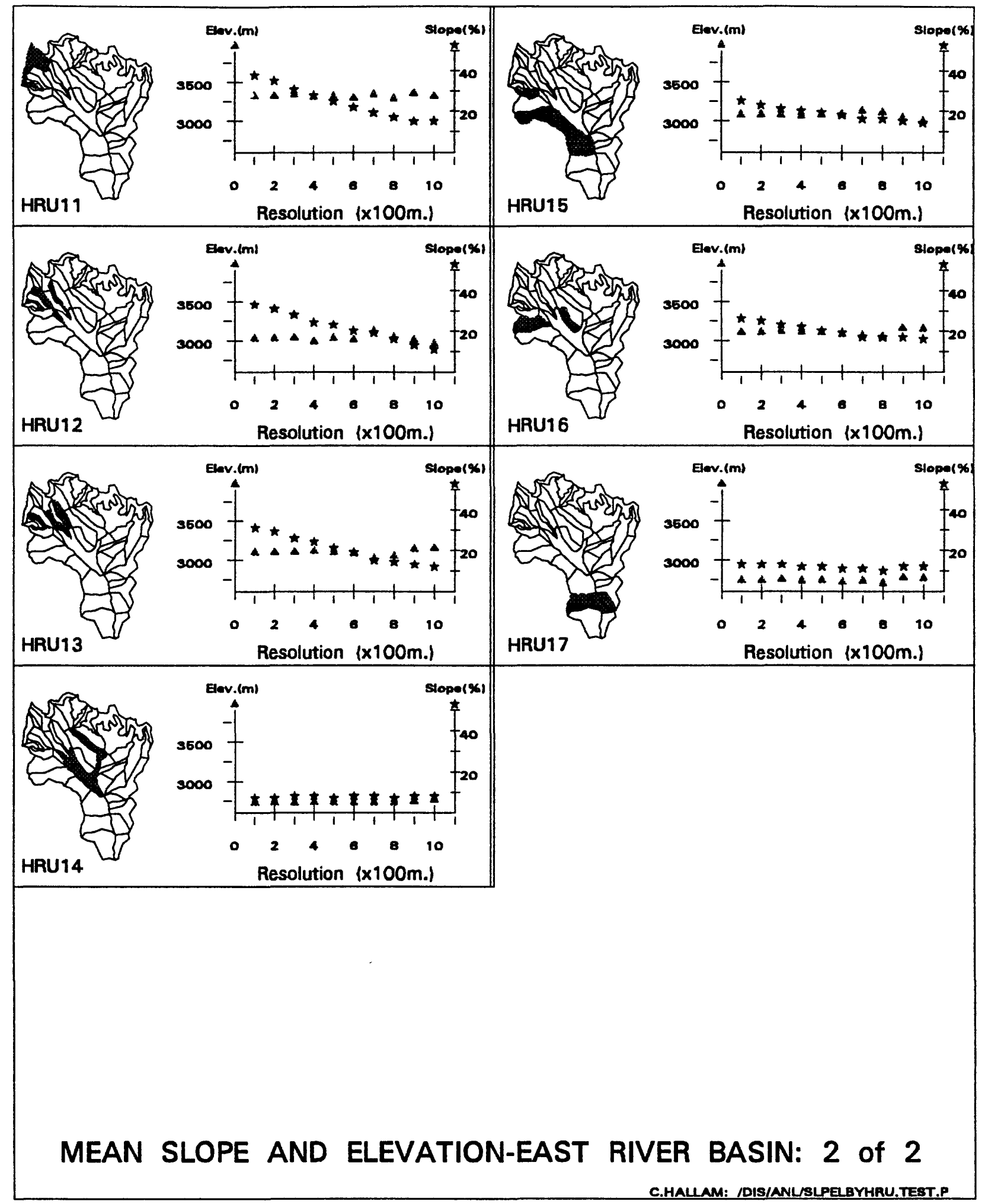

Figure 5b. Plots of mean elevation and slope for HRU's 11-17 in the East River Basin. 


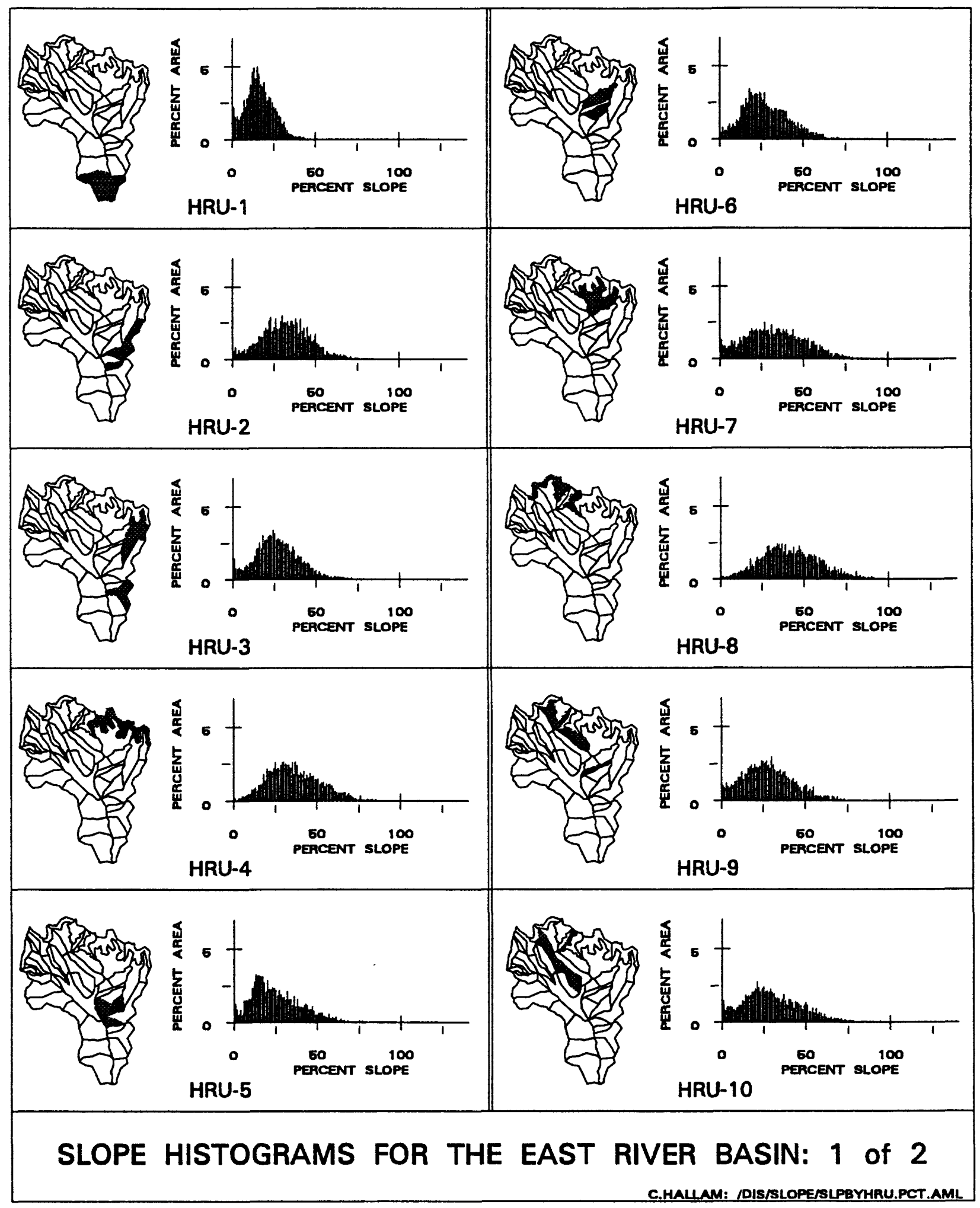

Figure 6a. Slope distribution histograms for HRU's 1-10 in the East River Basin. 


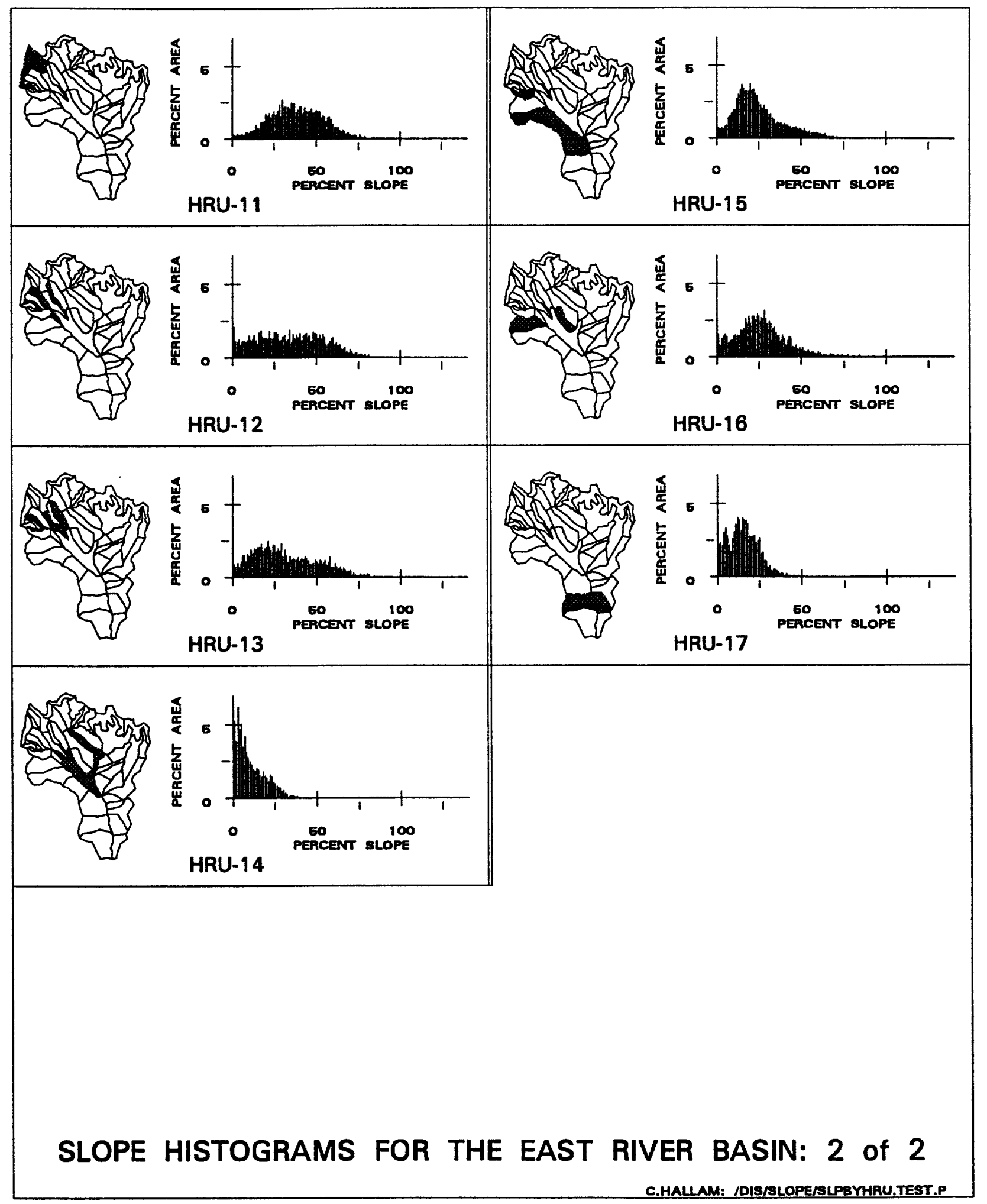

Figure 6b. Slope distribution histograms for HRU's 11-17 in the East River Basin. 


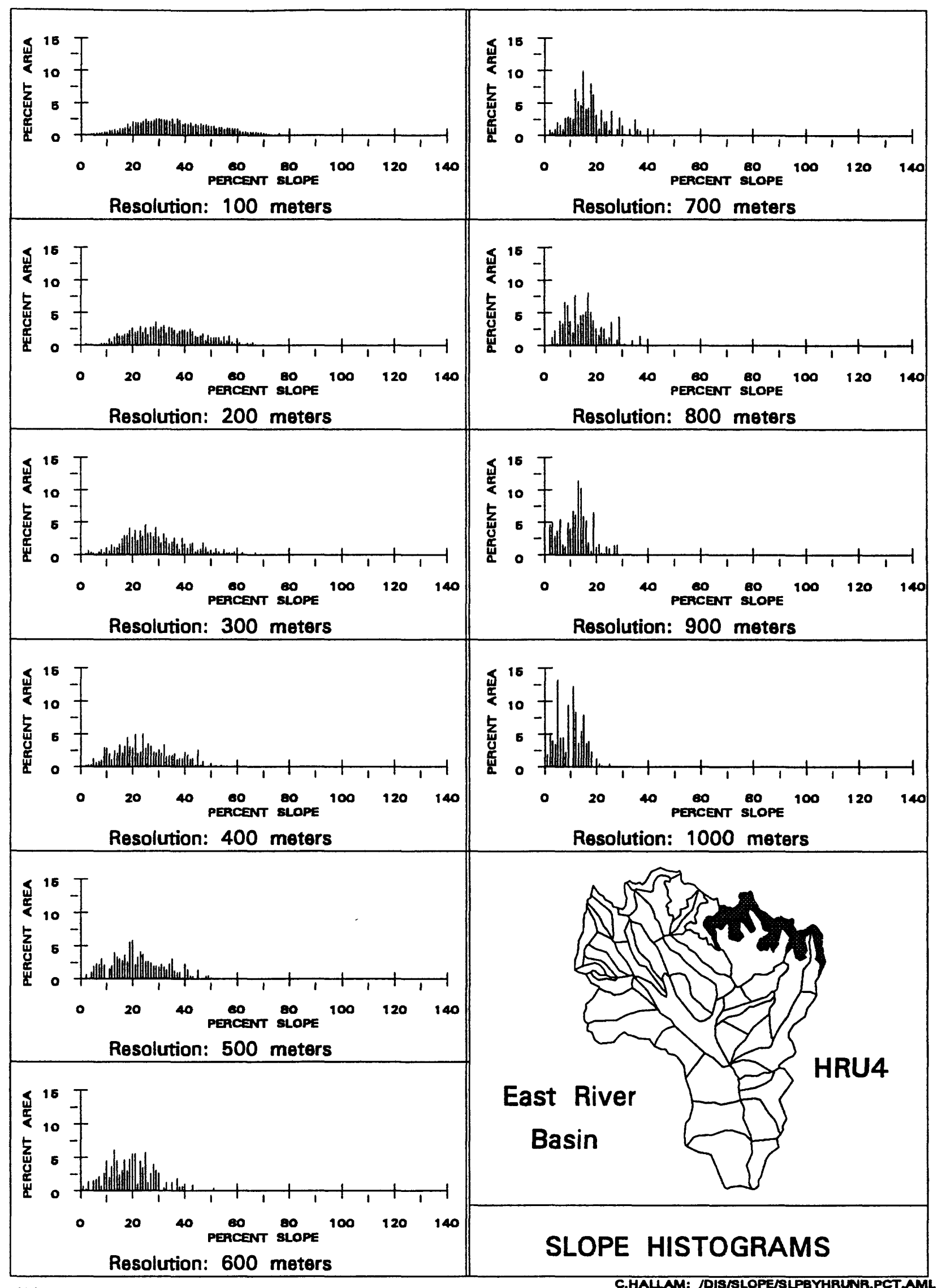

Figure 7. Slope distribution histograms for HRU 4 at each resolution. 


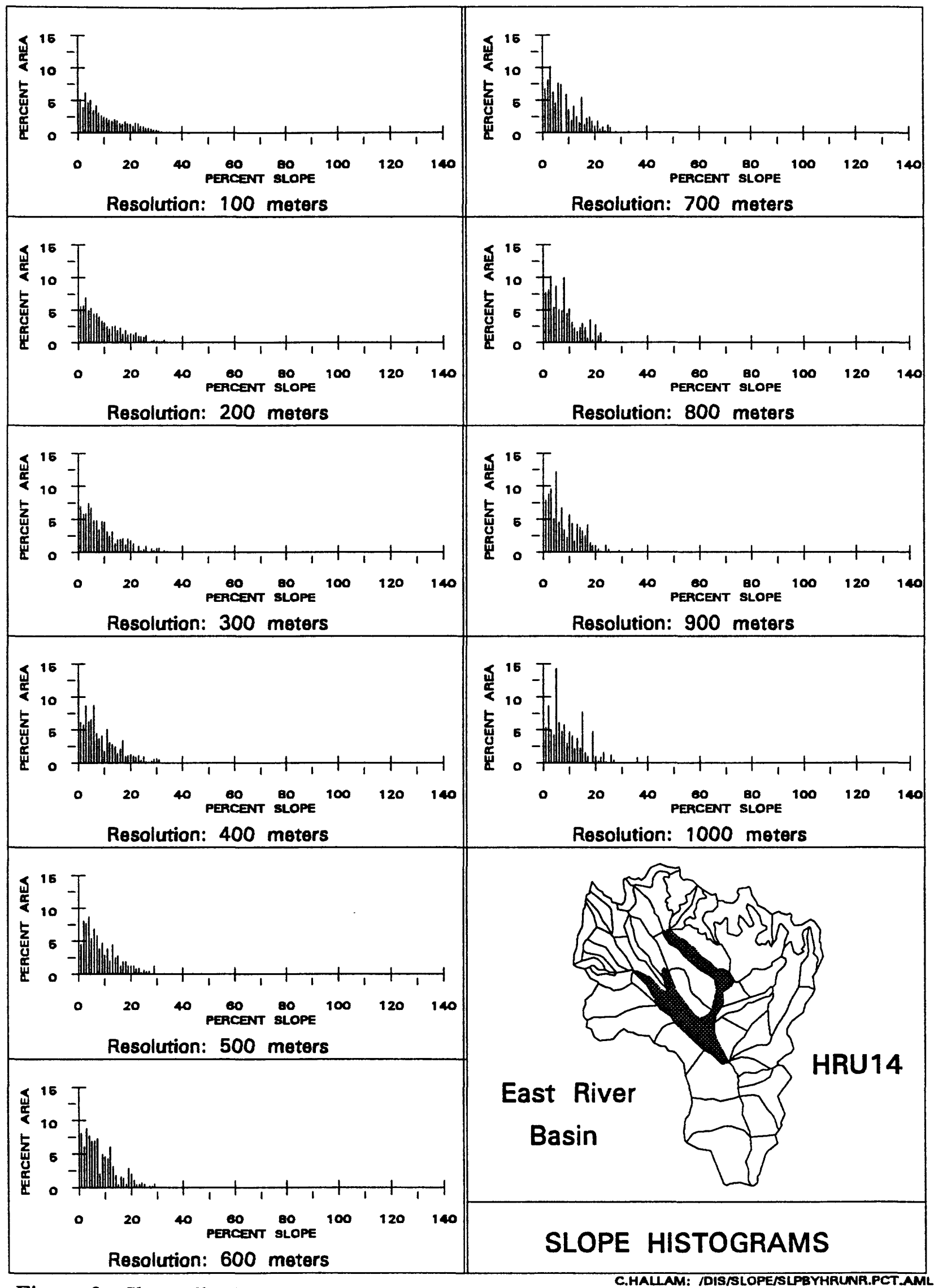

Figure 8. Slope distribution histograms for HRU 14 at each resolution. 


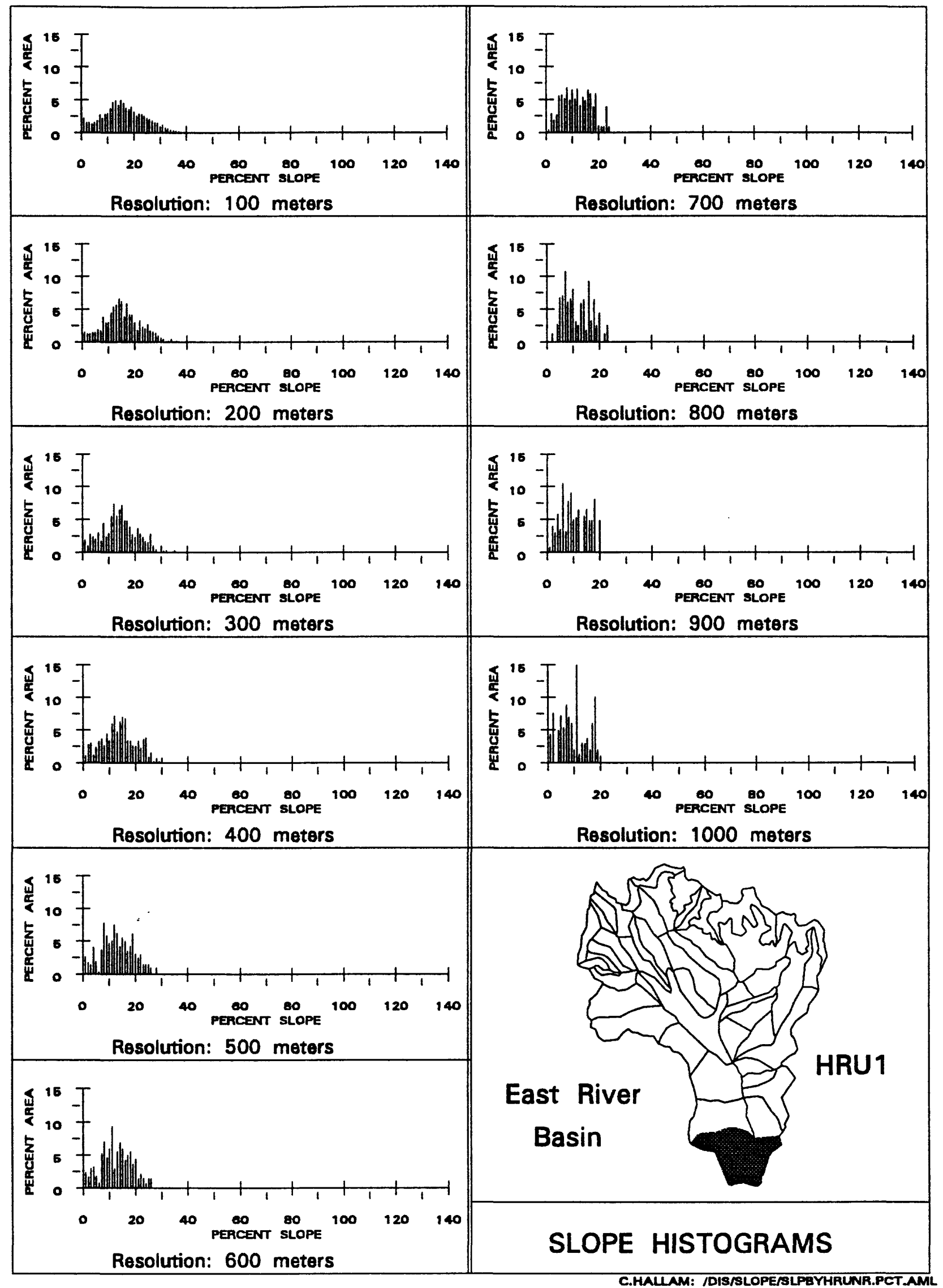

Figure 9. Slope distribution histograms for HRU 1 at each resolution. 
When aspect was examined as displayed in table 5, there were many changes in the aspect of HRU's with declining resolution, but those changes were not always consistent in direction of change nor were they maintained throughout the generalization process. Some of the changes seen at intermediate resolution levels were gone by the time the 1000 meter cell size was reached (HRU's 3, 5, 11, 13, and 14). The few HRU's that maintained the same aspect were those that had strong concentrations centered on one aspect zone (e.g. HRU's 9, 10, and 15 in figure 10). Those that had no dominant aspect, a concentration that centered between two zones, or a strong bimodal tendency in figure 10, experienced the largest number of changes in table 5 .

Table 5. Dominant aspect for each HRU at each resolution (meters).

\begin{tabular}{|r|l|l|l|l|l|l|l|l|l|l||}
\hline HRU & 100 & 200 & 300 & 400 & 500 & 600 & 700 & 800 & 900 & 1000 \\
\hline 1 & ENE & E & ENE & ENE & ENE & E & E & E & E & E \\
\hline 2 & NW & NW & NW & NW & WNW & WNW & WNW & WNW & WNW & WNW \\
\hline 3 & SW & SW & SE & SW & SE & SW & SSW & SW & SW & SW \\
\hline 4 & SW & SW & SW & SE & SW & SE & SW & SE & SE & SE \\
\hline 5 & SW & SW & SW & SE & SW & SW & SW & SW & SW & SW \\
\hline 6 & NW & NW & NW & NW & NW & NW & NW & WNW & WNW & WNW \\
\hline 7 & WSW & WSW & WSW & WSW & SW & SW & SE & SW & SW & SW \\
\hline 8 & SW & SE & SW & SE & SE & SE & SW & SE & SW & ESE \\
\hline 9 & SW & SW & SW & SW & SW & SW & SW & SW & SW & SW \\
\hline 10 & ENE & ENE & ENE & ENE & ENE & ENE & ENE & ENE & ENE & ENE \\
\hline 11 & SE & ESE & ESE & ESE & ESE & ESE & ESE & ESE & SE & SE \\
\hline 12 & NE & NE & NE & NE & NE & NE & ENE & NE & E & ENE \\
\hline 13 & SW & SW & SW & SSW & SW & SW & SW & SW & SW & SW \\
\hline 14 & SW & SW & SW & SW & SW & SW & NE & SW & SW & SW \\
\hline 15 & NE & NE & NE & NE & NE & NE & NE & NE & NE & NE \\
\hline 16 & SW & SW & SW & SE & SW & SW & SW & SW & SW & SE \\
\hline 17 & SE & SE & SE & SE & SE & SE & SE & SE & SE & SW \\
\hline \hline
\end{tabular}

Some of the changes that occurred as a result of generalization had no real effect on the model results because NE and NW (as well as E and W, and SE and $\mathrm{SW})$ produce equivalent results in the model used here. The fact that slope seems to be affected more by changes in resolution than aspect may be a result of the techniques used to derive them. The slope is the simple average of the slope of all the cells which compose each HRU, which provides an easy mechanism to measure change. Because aspect is more complex to derive for the HRU's, leading to a nominal description, it seems reasonable that its changes would be more difficult to track. 


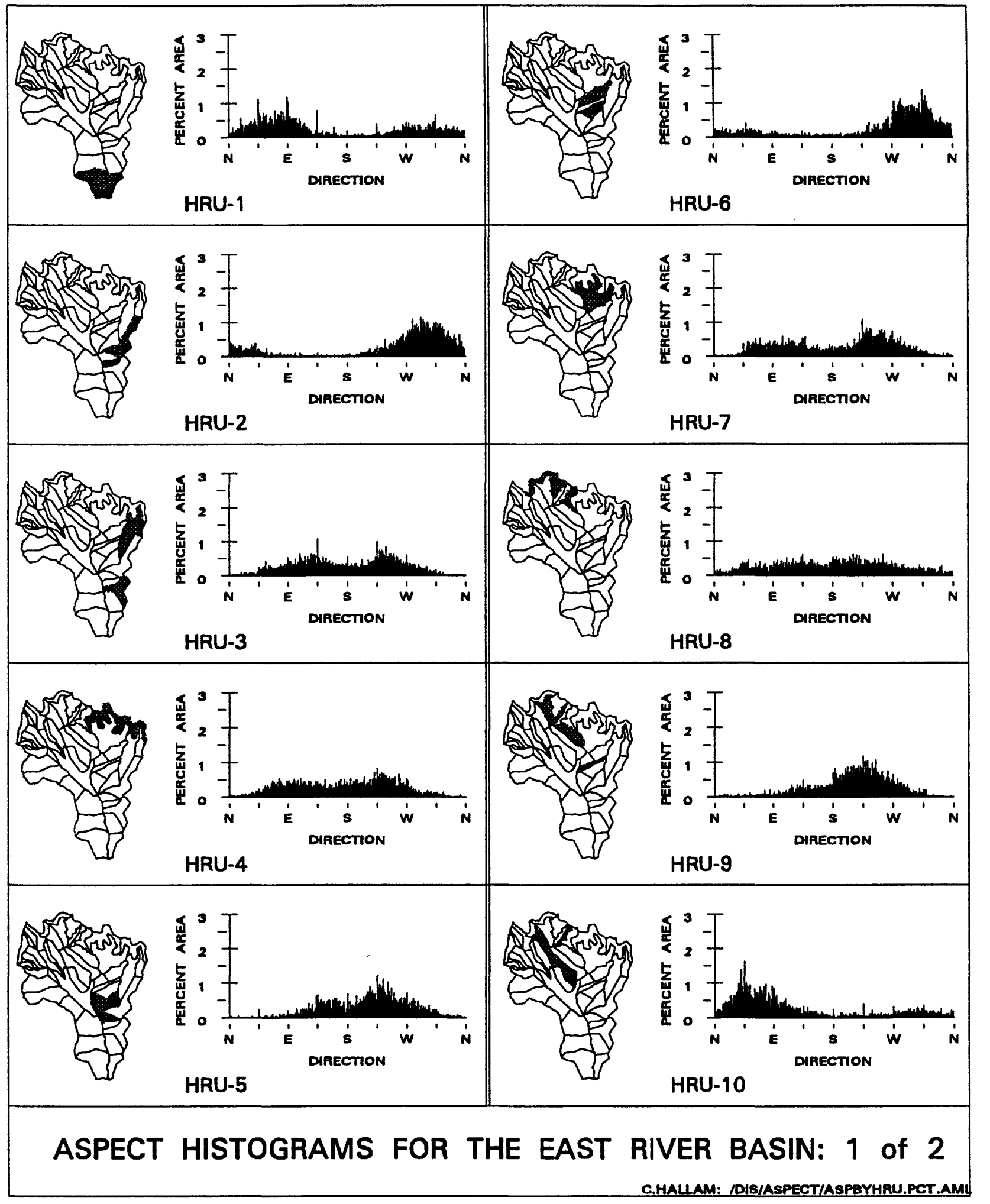

Figure 10a. Aspect distribution histograms for HRU's 1-10 in the East River Basin. 


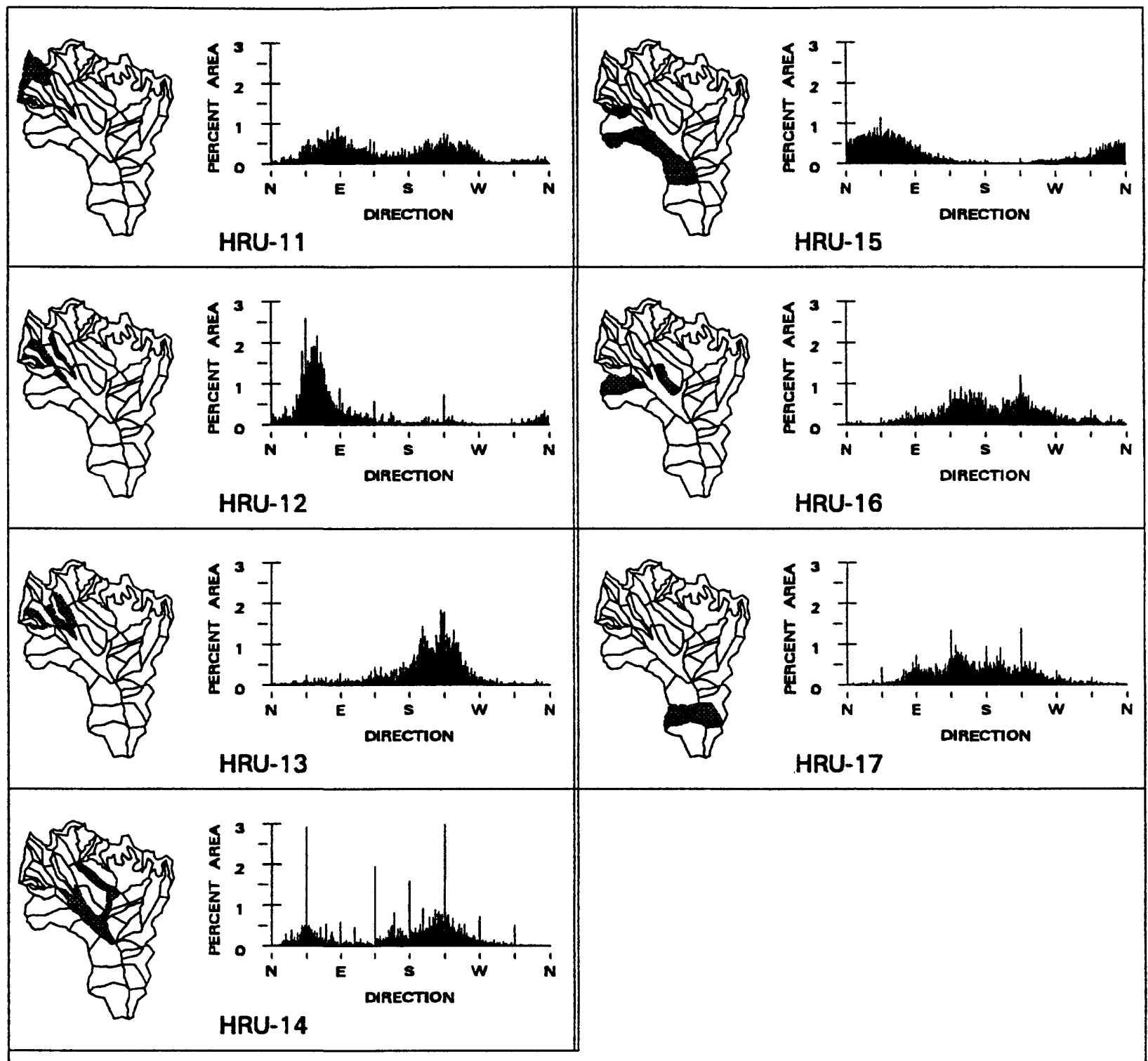

ASPECT HISTOGRAMS FOR THE EAST RIVER BASIN: 2 of 2 C.HALLAM: /DIS/ASPECTIASPGYHRU.TEST.P

Figure 10b. Aspect distribution histograms for HRU's 11-17 in the East River Basin. 
To further assess the effect of resolution on slope and aspect, a paireddifference $t$-test was run. The results of the paired-difference $t$-test which are displayed in table 6 show that the slope varies significantly at the 0.01 level when generalized from 100 to 1000 meters, which supports the earlier evidence. The change in aspect based on generalization was much less significant, only becoming significant beyond the 0.2 or 0.11 level when computed using either the aspect angle or its cosine, respectively. This also supports the earlier findings that suggest a somewhat weak correlation between aspect and resolution when evaluated numerically, but a more understandable relationship when viewed more intuitively, as shown by the concentration of aspect around certain aspect directions in figure 10.

The graphs of slope and elevation in figure 5 and histograms of slope for each of the HRU's in figure 6 suggest little relationship between mean HRU elevation and generalization-produced slope change. In an attempt to better assess the relationship of other physical parameters to slope change, a regression was run to test the significance of elevation range and mean slope to slope change. In table 7 , the regression between slope change (from 100 to 1000 meters) and both mean slope and elevation range (100 meters) demonstrate that the relationship between slope change and mean slope is significant well beyond the 0.01 level. However, the relationship between slope change and elevation range is not as strong, only becoming significant at the 0.03 level. Both play a role in the size of the change in HRU slope because the size of the mean slope at 100 meters determines the range of slope changes available and the elevation is an indication of potential slope. In this basin the highest slopes (e.g. HRU's 4 and 8), which were the most distant from the mouth, showed the highest slope change with generalization, which follows logically from the findings that large slopes are smoothed by generalization and that the highest elevations are smoothed most.

Table 6. T statistics for the HRU slope and aspect estimates - comparing 1000 meter data and 100 meter data.

\begin{tabular}{||l|r|r|}
\hline $\begin{array}{l}\text { Data } \\
\text { Type }\end{array}$ & T-Statistic & Prob $>|T|$ \\
\hline Slope & 17.551 & 0.0001 \\
\hline Aspect & -1.322 & 0.2047 \\
\hline $\begin{array}{l}\text { Aspect } \\
\text { (cosine) }\end{array}$ & -1.686 & 0.1112 \\
\hline
\end{tabular}


Table 7. Regression analysis output for slope change (mean slope $e_{100}$ - mean slope ${ }_{1000}$ ) on mean slope and elevation range.

\begin{tabular}{||l|c|c|c|r|r||}
\hline \multicolumn{1}{|c|}{ Variable } & $\begin{array}{c}\text { Degrees } \\
\text { of } \\
\text { Freedom }\end{array}$ & $\begin{array}{c}\text { Parameter } \\
\text { Estimate }\end{array}$ & $\begin{array}{c}\text { Standard } \\
\text { Error }\end{array}$ & $\begin{array}{c}\mathrm{T} \\
\text { Statistic }\end{array}$ & $\begin{array}{c}\text { Prob > } \\
|\mathrm{T}|\end{array}$ \\
\hline Intercept & 1 & 6.126212 & 2.588785 & -2.366 & 0.0329 \\
\hline $\begin{array}{l}\text { Mean slope } \\
\text { (100 meters) }\end{array}$ & 1 & -0.977173 & 0.063369 & 15.420 & 0.0001 \\
\hline $\begin{array}{l}\text { Elevation } \\
\text { range }\end{array}$ & 1 & 0.007309 & 0.003036 & -2.407 & 0.0304 \\
\hline
\end{tabular}

\section{Comparison of Model Results}

Any statements about the accuracy of either of the two estimates are suspect because of the fact that the model was calibrated to a small degree before this experiment (using data with a resolution closer to the 1000 meter data than the 100 meter data) and no calibration has been done since then. The primary concern of this study is the comparison of the two predicted flows. The comparisons of model results to the observed runoff figures are simply to provide a basis for the comparison of the predictions to each other.

The hydrographs of predicted daily runoff for water year 1983 (WY83) plotted with actual recorded runoff in figures $11 \mathrm{a}$ and $11 \mathrm{~b}$ show that the predictions from 100 and 1000 meter data generally agree with the actual values, which justifies use of the PRMS model for the purposes of this research. Figure 11c simply compares the two predictions of daily runoff for WY83 demonstrating that although the two hydrographs are extremely similar, there are some differences even at this scale of representation. Monthly runoff totals when plotted against the observed values also display general agreement, as seen in figures $12 \mathrm{a}$ and $12 \mathrm{~b}$. They show a definite trend along the $45^{\circ}$ line but vary from the line as well. The plot of 100 meter predictions against 1000 meter predictions, figure $12 \mathrm{c}$, shows very strong agreement between the two predictions when presented as monthly runoff totals.

Correlations $\left(\mathrm{r}^{2}\right)$ between the observed and predicted runoff values at daily, monthly, and annual resolutions showed strong agreement, as can be seen in table 8. The highest correlations were found in the monthly runoff data predicted using the 100 meter data. The correlation between the 100 and 1000 meter predictions at each temporal resolution was very high, with the lowest being .9951 for the daily and the highest .9997 for the annual runoff predictions. This comparison alone is not enough to determine whether or not there is an important difference between the predictions. 

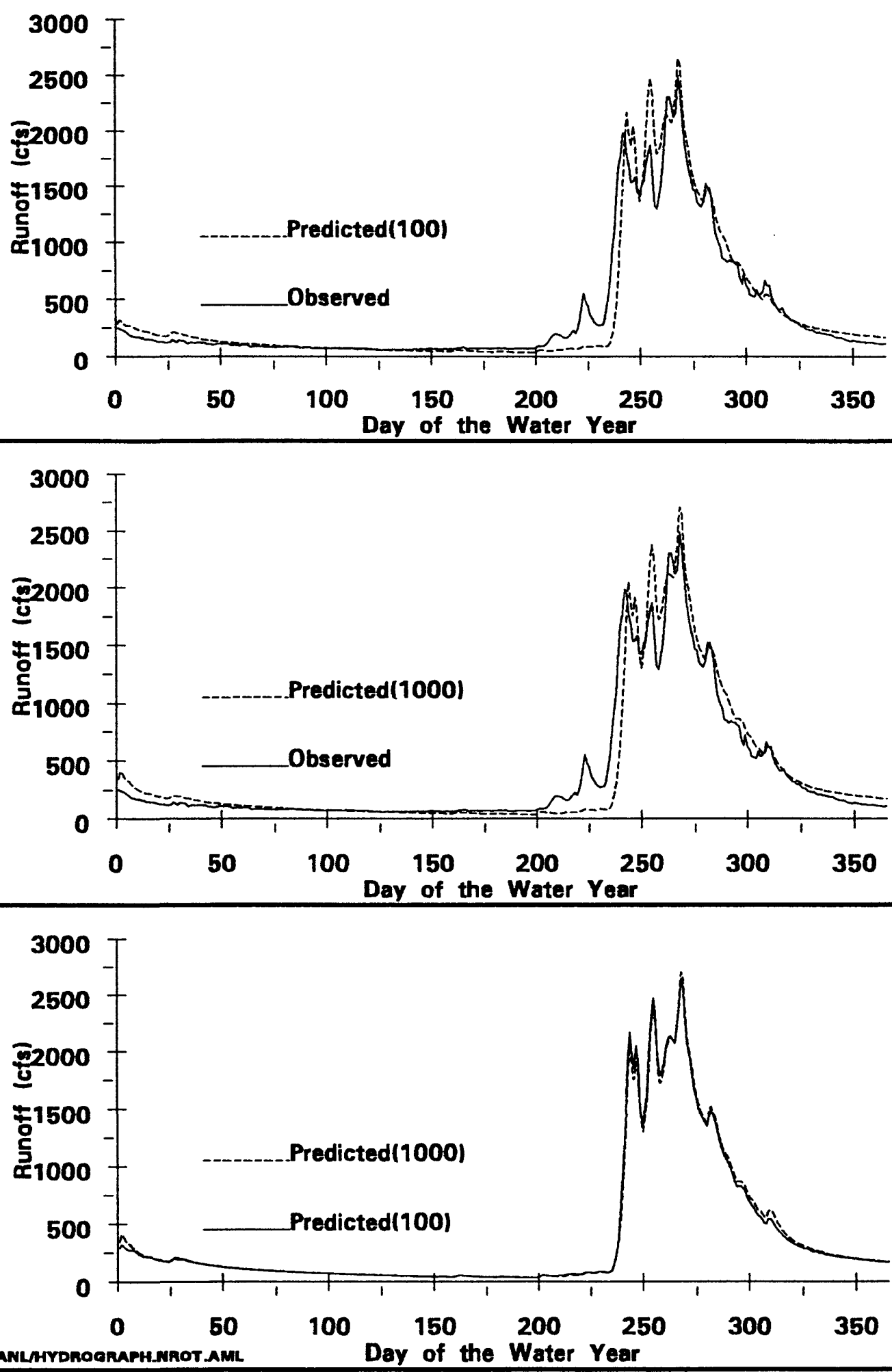

Figure 11. Hydrographs for water year 1983 of observed and predicted (100 meter) daily runoff (a); hydrograph of observed and predicted (1000 meter) daily runoff (b); and hydrograph of predicted daily runoff at both 100 and 1000 meters (c). 


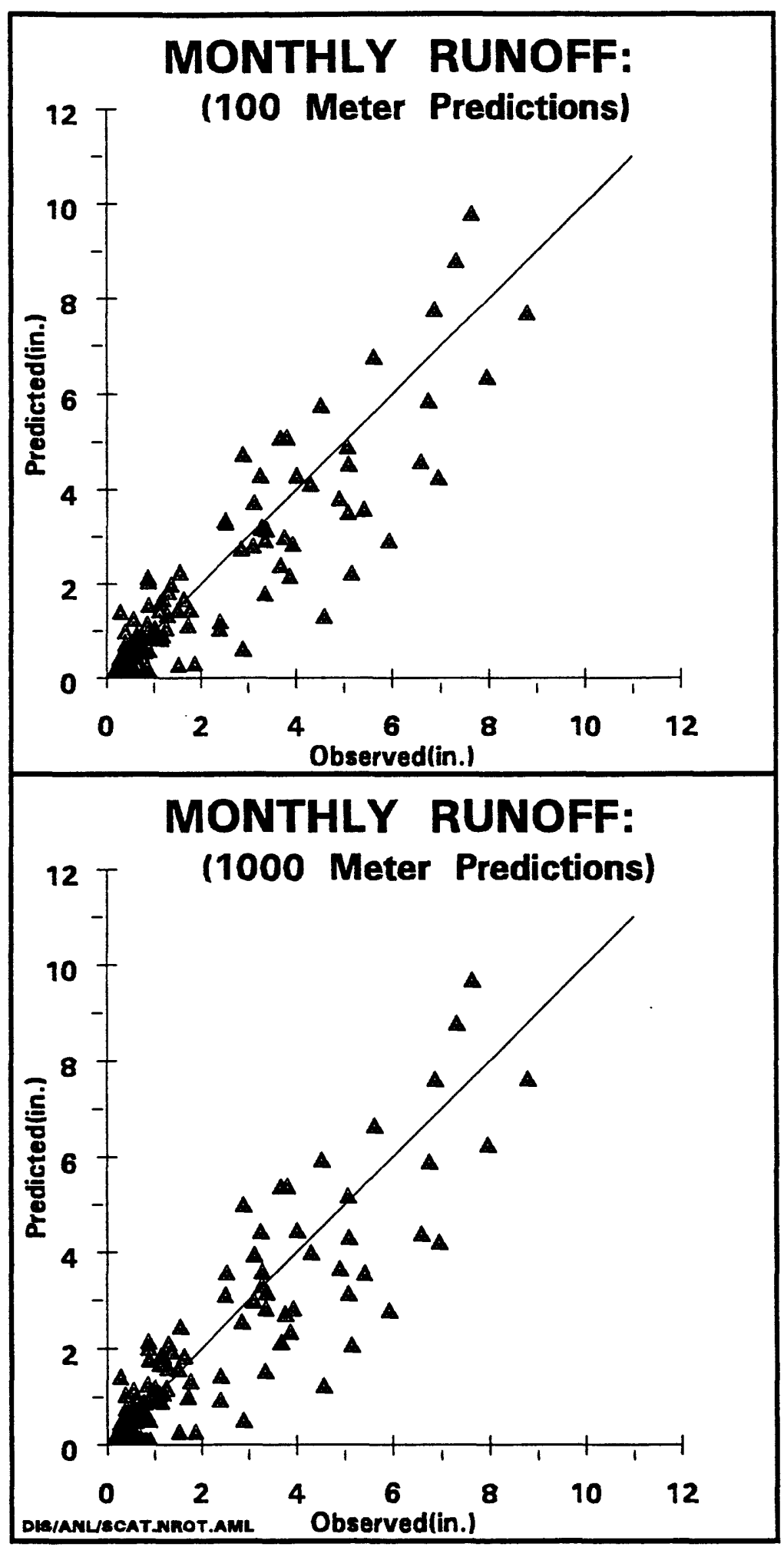

Figure 12. (a) Plot of observed monthly runoff totals against predicted (a) 100 meter runoff and (b) 1000 meter runoff. 
In figure 13a the plot of 100 meter versus 1000 meter predicted annual runoff totals shows a slight bias in nearly all of the years of record. Only one of the years appears to produce higher total annual runoff using the 1000 meter data than the 100 meter data. In figure $13 \mathrm{~b}$, the monthly runoff totals present a slightly different picture, with runoff totals less than 3 inches clustering fairly evenly around the 45 degree line, while the 100 meter runoff totals between 3 and 5 inches are predominantly higher, and the 100 meter predictions that exceeded 6 inches are exclusively greater than the 1000 meter totals.

Table 8. Correlations $\left(r / r^{2}\right)$ between observed and predicted runoff totals.

\begin{tabular}{|c|c|c|c|c|}
\hline $\begin{array}{l}\text { Temporal } \\
\text { Resolution }\end{array}$ & $\begin{array}{c}\text { Spatial } \\
\text { Resolution }\end{array}$ & Observed & Predicted $_{100}$ & Predicted $_{1000}$ \\
\hline \multirow{3}{*}{ Annual } & Observed & 1.00000 & $\begin{array}{l}0.89928 \\
0.80871\end{array}$ & $\begin{array}{l}0.89933 \\
0.80879\end{array}$ \\
\hline & Predicted $_{100}$ & & 1.00000 & $\begin{array}{l}0.99986 \\
0.99972\end{array}$ \\
\hline & Predicted $_{1000}$ & & & 1.00000 \\
\hline \multirow{3}{*}{ Monthly } & Observed & 1.00000 & $\begin{array}{l}0.92124 \\
0.84868 \\
\end{array}$ & $\begin{array}{l}0.91046 \\
0.82894 \\
\end{array}$ \\
\hline & Predicted $_{100}$ & & 1.00000 & $\begin{array}{l}0.99830 \\
0.99660\end{array}$ \\
\hline & Predicted $_{1000}$ & & & 1.00000 \\
\hline \multirow{3}{*}{ Daily } & Observed & 1.00000 & $\begin{array}{l}0.89789 \\
0.80621\end{array}$ & $\begin{array}{l}0.88956 \\
0.79148 \\
\end{array}$ \\
\hline & Predicted $_{100}$ & & 1.00000 & $\begin{array}{l}0.99754 \\
0.99509 \\
\end{array}$ \\
\hline & Predicted $_{1000}$ & & & 1.00000 \\
\hline
\end{tabular}




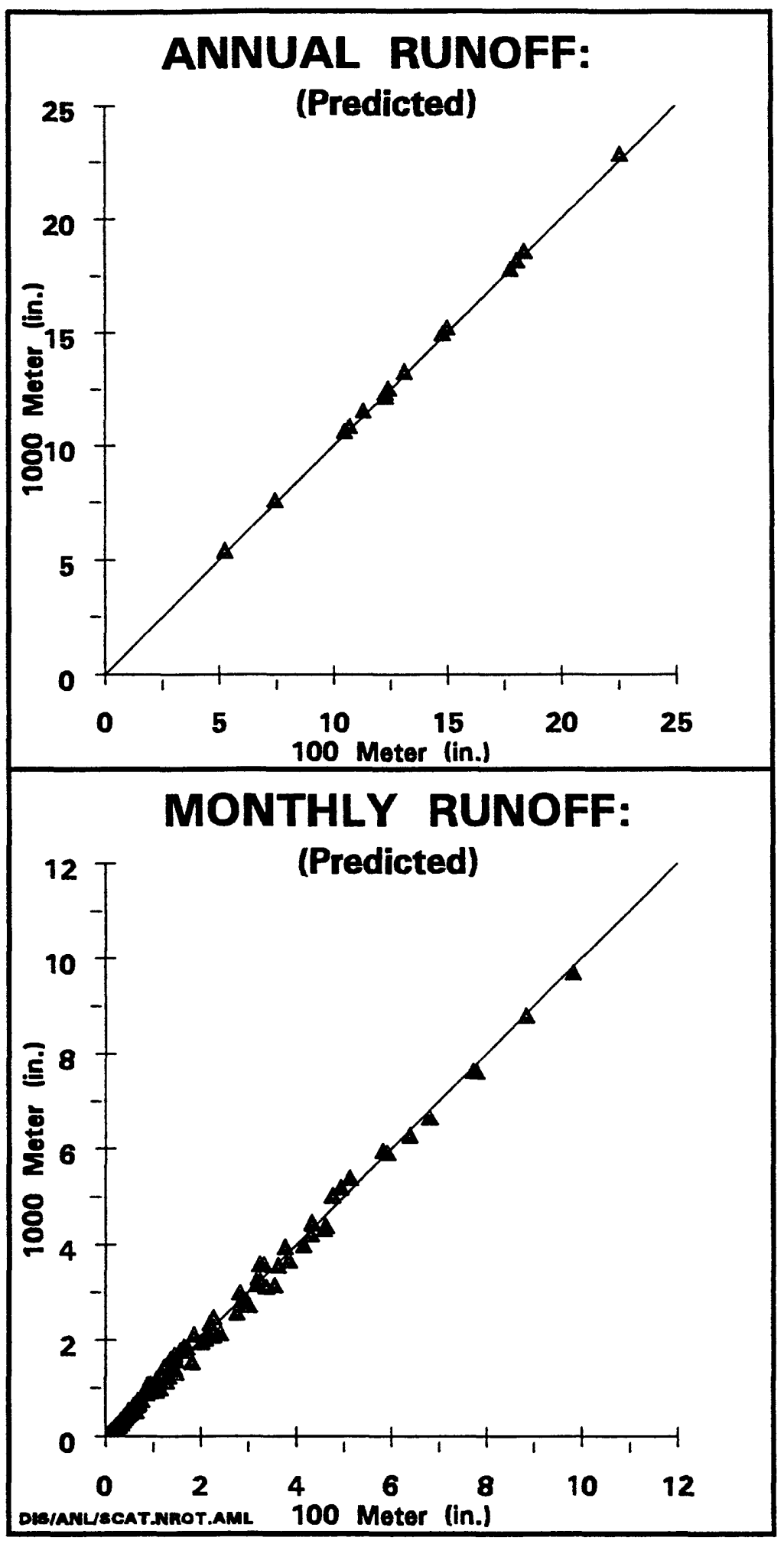

Figure 13. Plot of predicted runoff from 100 meter data versus 1000 meter data for (a) annual totals and (b) monthly totals. 
Table 9 shows the general information conveyed in figure 13b. It lists the differences between the 100 and 1000 meter annual predictions, which confirm that the 1000 meter predictions exceed the 100 meter predictions in all but one of the 17 years tested. Annual totals exhibit strong agreement when compared based on their percent difference.

Table 9. Differences between annual runoff predictions (in inches) based on 100 versus 1000 meter data.

\begin{tabular}{|r|r|r|r|r|c||}
\hline $\begin{array}{r}\text { Water } \\
\text { Year }\end{array}$ & $\begin{array}{r}\text { Total } \\
\text { Runoff } \\
(100 \mathrm{~m})\end{array}$ & $\begin{array}{c}\text { Total } \\
\text { Runoff } \\
(1000 \mathrm{~m})\end{array}$ & $\begin{array}{c}\text { Difference } \\
\text { (inches) } \\
(1000 \mathrm{~m}-100 \mathrm{~m})\end{array}$ & $\begin{array}{c}\text { Difference } \\
\text { (percent) }\end{array}$ & $\begin{array}{c}\text { Months } \\
5 \% \\
\text { Difference }\end{array}$ \\
\hline 1973 & 12.294 & 12.250 & -0.044 & -0.4 & 4 \\
\hline 1974 & 10.489 & 10.711 & 0.222 & 2.1 & 2 \\
\hline 1975 & 13.123 & 13.356 & 0.233 & 1.8 & 9 \\
\hline 1976 & 10.706 & 10.931 & 0.225 & 2.1 & 5 \\
\hline 1977 & 5.254 & 5.466 & 0.212 & 4.0 & 4 \\
\hline 1978 & 17.787 & 17.876 & 0.091 & 0.5 & 4 \\
\hline 1979 & 15.014 & 15.274 & 0.260 & 1.7 & 5 \\
\hline 1980 & 14.808 & 15.039 & 0.231 & 1.6 & 4 \\
\hline 1981 & 7.425 & 7.653 & 0.228 & 3.1 & 5 \\
\hline 1982 & 18.416 & 18.649 & 0.233 & 1.3 & 4 \\
\hline 1983 & 18.077 & 18.246 & 0.169 & 1.0 & 3 \\
\hline 1984 & 22.583 & 22.915 & 0.333 & 1.5 & 3 \\
\hline 1985 & 18.399 & 18.667 & 0.268 & 1.5 & 3 \\
\hline 1986 & 25.348 & 25.588 & 0.240 & 1.0 & 5 \\
\hline 1987 & 12.414 & 12.626 & 0.212 & 1.7 & 5 \\
\hline 1988 & 12.278 & 12.416 & 0.138 & 1.1 & 4 \\
\hline 1989 & 11.294 & 11.616 & 0.322 & 2.8 & 4 \\
\hline Total & 245.71 & 249.78 & 3.661 & 29.2 & 73 \\
\hline & & & & & \\
\hline
\end{tabular}


The largest percent difference occurred in the 1977 water year which was the driest year on record. The largest absolute difference occurred in 1984 which was the second wettest. Differences in monthly totals shown in the far right column of table 9 , reveal possible trends in the temporal variation produced by data generalization when displayed in table 10. Simple percent differences calculated for each month displayed a definite change in temporal distribution of predicted runoff when generalized elevation parameters were used. Runoff predicted by both the 100 and 1000 meter data wasover-estimated in the summer months and under-estimated in the spring when compared to the observed runoff. The 1000 meter predictions also exceeded the 100 meter predictions during the summer months in all years and fell below the 100 meter predictions in the spring in most months. July, August and September were the most noticeable months where all of the 1000 meter predictions exceeded the 100 meter predictions. The 1000 meter data exceeded the 100 meter predictions of runoff by more than 5 percent more than one half of the time in September, all but two years in July, and all but one year in August.

The 1000 meter predictions were more than 5 percent less than the 100 meter predictions only during the months of April and May. With the exception of 1975, which appears to be anomalous, the 1000 meter predictions never exceeded the 100 meter predictions in May or in April.

Table 10. Over (+) and under predictions (-) of runoff (more than 5\%) by the 1000 meter predictions when compared to the 100 meter predictions.

\begin{tabular}{||l|l|l|l|l|l|l|l|l|l|l|l|l||}
\hline Year & OCT & NOV & DEC & JAN & FEB & $\begin{array}{c}\text { MA } \\
\text { R }\end{array}$ & APR & MAY & JUN & JUL & AUG & SEP \\
\hline 1973 & & & & & & & - & - & & + & + & \\
\hline 1974 & & & & & & & & & & + & + & + \\
\hline 1975 & + & + & + & + & + & + & + & - & & & + & + \\
\hline 1976 & & & & & & & - & - & & + & + & + \\
\hline 1977 & + & & & & & & - & & + & + & & \\
\hline 1978 & & & & & & & - & - & & + & + & \\
\hline 1979 & & & & & & & - & - & & + & + & + \\
\hline 1980 & & & & & & & & & + & + & + & \\
\hline 1981 & & & & & & & - & - & + & + & + & + \\
\hline 1982 & & & & & & & & - & & + & + & + \\
\hline 1983 & + & & & & & & & - & & & + & \\
\hline 1984 & + & & & & & & & & & + & + & \\
\hline 1985 & & & & & & & - & & & + & + & \\
\hline 1986 & & & & & & & - & - & & + & + & + \\
\hline 1987 & & & & & & & - & & + & + & + & + \\
\hline 1988 & & & & & & & - & - & & + & + & + \\
\hline 1989 & & & & & & & - & & & + & + & + \\
\hline
\end{tabular}


In order to further examine the significance of the seasonal variation in the runoff predictions at different resolutions, paired difference t-tests, were run on the annual runoff totals. The test results in table 11 show that the difference between the two runoff estimates is significant at the .01 level. When evaluated using the absolute value of the differences, the 100 meter and 1000 meter annual totals differ significantly from the observed at the .01 level as does the difference between the two predictions from zero according to the t-test. However, when the actual differences are tested, their difference from the observed is much less significant. In fact, the 1000 meter estimate appears to be slightly more accurate than the 100 meter estimate according to the significance test. Both Prob $>|\mathrm{T}|$ values are close to the 0.05 significance level, but using that limit for the test, the 100 meter results would be significantly different and the 1000 meter estimate would not. This suggests that for the annual predictions, the 100 and 1000 meter elevation data are fairly comparable.

Table 11. T-statistics for annual runoff during the 17 years of the test.

\begin{tabular}{||c||r|r||}
\hline & T Statistic & Prob $>|T|$ \\
\hline \hline A $=\mid$ Predicted $_{100}$-Observed $\mid$ & 9.561 & 0.0001 \\
\hline B $=\mid$ Predicted $_{1000}$-Observed $\mid$ & 9.700 & 0.0001 \\
\hline B-A & -4.303 & 0.0001 \\
\hline C $=$ Predicted $_{100}$-Observed & -2.345 & 0.0322 \\
\hline D $=$ Predicted $_{1000}$-Observed & -1.983 & 0.0648 \\
\hline D-C & 9.899 & 0.0001 \\
\hline
\end{tabular}

The paired-difference $t$-test was used to assess the statistical significance of the monthly resolution-produced differences in predicted runoff. The results of the t-tests run on the monthly data, displayed in table 12 , show both the 100 meter and 1000 meter predictions to vary similarly from the observed runoff; significant differences exist at the .05 level between the two predictions in every month except June.

The plot of errors for the difference between the predictions at the two resolutions shown in figures $14 \mathrm{a}$ and $14 \mathrm{~b}$ clearly demonstrate the temporal differences in the distribution of the runoff throughout the year. Compared to the 100 meter data, the 1000 meter data predict more runoff during the summer and less in the spring. This difference helps to explain the lack of significant difference between the estimates for the month of June. It appears that the model is in transition from underprediction to overprediction, and in the month of crossover, as shown in table 12, the errors balance each other out with equal underprediction and overprediction. If this is the case, then the two models predict equally well during June. 
Table 12. Results of the Paired-Difference t-test for predicted runoff. Tests run comparing observed to predicted monthly and annual runoff totals, including the absolute value of the total annual runoff.

\begin{tabular}{|c|c|c|c|}
\hline MONTH & ERROR $_{100}$ & $\begin{array}{c}\text { ERROR }_{100} \\
0 \\
\end{array}$ & $\begin{array}{c}\text { ERROR }_{1000}- \\
\text { ERROR }_{100} \\
\end{array}$ \\
\hline October & $\mathbf{R}$ & $\mathbf{R}$ & $\mathbf{R}$ \\
\hline November & A & A & $\mathbf{R}$ \\
\hline December & A & A & $\mathbf{R}$ \\
\hline January & $\mathbf{R}$ & $\mathbf{R}$ & $\mathbf{R}$ \\
\hline February & $\mathrm{R}$ & $\mathrm{R}$ & $\mathbf{R}$ \\
\hline March & $\mathbf{R}$ & $\mathbf{R}$ & $\mathrm{R}$ \\
\hline April & $\mathbf{R}$ & $\mathbf{R}$ & $\mathbf{R}$ \\
\hline May & $\mathrm{R}$ & $\mathbf{R}$ & $\mathbf{R}$ \\
\hline June & $\mathrm{A}$ & A & A \\
\hline July & $\mathbf{R}$ & $\mathbf{R}$ & $\mathbf{R}$ \\
\hline August & A & A & $\mathbf{R}$ \\
\hline September & $\mathbf{R}$ & $\mathbf{R}$ & $\mathbf{R}$ \\
\hline Annual & $\mathbf{R}$ & A & $\mathbf{R}$ \\
\hline |Annual| & $\mathbf{R}$ & $\mathbf{R}$ & A \\
\hline
\end{tabular}

$\mathrm{R}$ indicates the rejection of the null hypothesis at .05

A indicates the acceptance of the null hypothesis at .05

The statistical analysis displayed in table 12 supports both the acceptance and rejection of the null hypothesis for model results. While it must be rejected for predictions at the monthly resolution, it may be rejected or accepted for predictions at the annual resolution based on the type of difference studied. 


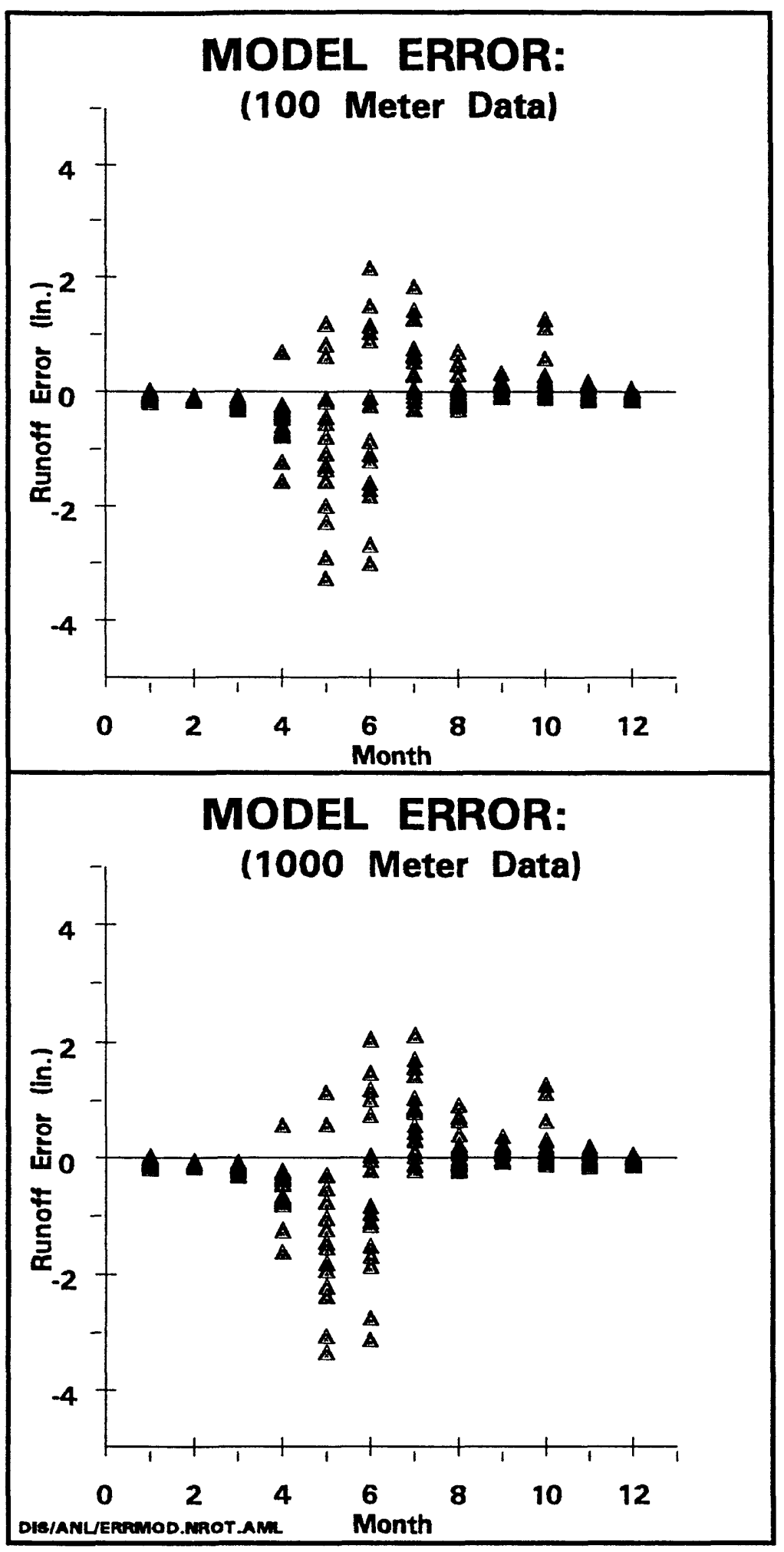

Figure $14 \mathrm{a}$ and $\mathrm{b}$. Plot of error for predicted total monthly runoff based on (a) 100 meters data, and (b) 1000 meter data. 


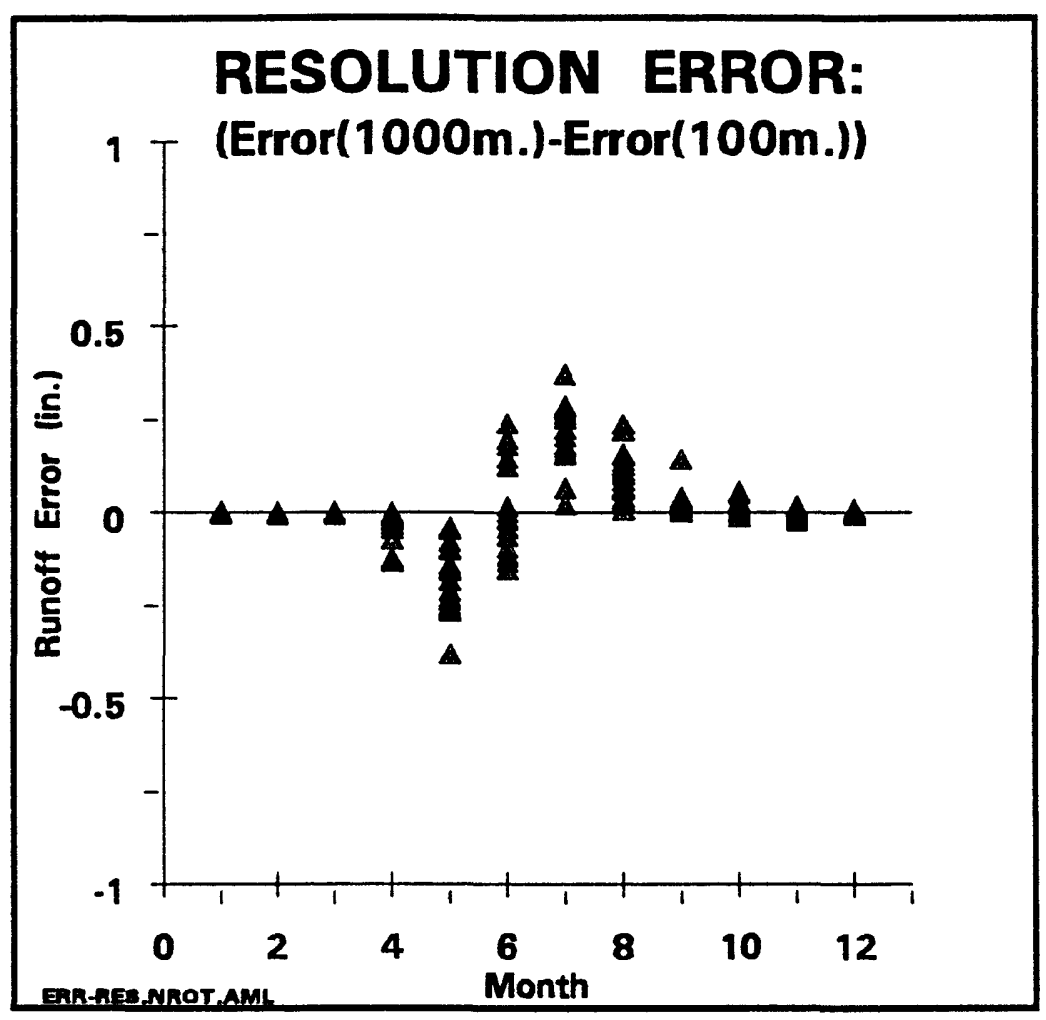

Figure 14c. Plot of error resulting from resolution change. 


\section{CONCLUSION}

Global change research and the applications of GCM output to regional level research and management problems concerning water supplies have emphasized the need for a better understanding of the effect of data resolution on the prediction of hydrologic response. This research has examined the sensitivity of a widely used precipitation-runoff model to the resolution of the elevation-based input data, by conducting a controlled experiment to determine the effect of these elevation-based parameters on the model. To that end, GIS techniques were used to generate elevation-based parameters (mean elevation, mean slope and dominant aspect) for the precipitation-runoff model at a variety of resolutions. These parameters were then tested for significant resolution-based changes at the basin and HRU level using paired-difference t-tests at the .05 significance level. Changes in these parameters were analyzed using regression techniques to assess their relationship with other physical characteristics (i.e. mean slope and elevation range). The Precipitation-Runoff Modeling System was used to generate daily runoff for the East River Basin for the period from October 1972 through September 1989 (WY73-WY89). The model was run using elevation data input at the 100 and 1000 meter resolutions. These results were tested using the paired-difference t-test to assess the significance of their differences from the observed runoff values and from each other.

When elevation, slope, and aspect were analyzed on a cell by cell basis, the correlation between the 100 and 1000 meter elevation data sets remained fairly constant. Both slope and aspect (cosine) changed significantly, demonstrating the smoothing effect of generalization. When slope and elevation were averaged over the basin, generalization had little effect on the values. The changes in mean slope resulting from generalization only became apparent when the mean slope was calculated for the individual HRU's. The ability of the HRU's to isolate the effect of generalization better than the larger basin demonstrates their utility to the modeling process. They provide a better description of the diversity within the basin than a full basin average, and are a more practical way to represent the basin than by its individual cells.

The change in spatial resolution of the elevation-based parameters significantly affected the prediction of hydrologic response, using the PrecipitationRunoff Modeling System at monthly time steps. The significance of the difference between the runoff estimates was a function of the temporal resolution at which the predictions were being made. In the prediction of annual runoff totals in the PRMS model, it appears that there is no need to use a resolution finer than 1000 meters for elevation data. If a finer temporal resolution is required (e.g. monthly totals), however, there is a significant difference between predictions at $100 \mathrm{~m}$ and $1000 \mathrm{~m}$ resolutions. The significance of the difference between the two predictions suggests 
that spatial generalization can have an impact on the prediction of runoff from the model.

Based on these findings the following three things should be considered:

1. It would be advisable for users of hydrologic models similar to this one to be careful in the selection of data resolution used; or based on the resolution of the data available for use in the study, they should carefully consider limits to the temporal resolution at which they can predict runoff.

2. The temporal distribution of underpredicitons and overpredictions discovered here may depend on the characteristics of the basin in which the model is being used. The East River Basin is an area of limited water resources, so temporal variations can be very important. Overpredictions of runoff at the time of year when water supplies are dwindling could lead to very serious miscalculations of the available water, which, in turn, could lead to incorrect water management and development decisions. If, on the other hand, the basin to be studied is one with ample water supply throughout the year, the temporal nature of the resolutionbased differences may be of less concern, and the high correlations between the predicted and observed flow would indicate that the model is adequate for the planned use.

3. The findings of this research are preliminary and are based on a specific model and basin applications of this or similar models to other areas may not produce the same results.

Much remains to be done in this area of research. Future studies need to further address the quality of the monthly predictions at both spatial resolutions to determine whether one is better than the other. In addition, more research must be done on a wider range of resolutions, climatic regimes, topographic regions, and models. The issue of HRU delineation is also one which needs further study, and GIS is beginning to provide the tools for those studies.

Some studies are already addressing the delineation of HRU's by the techniques mentioned earlier, but comparisons are needed of model results produced by different HRU's for the same study area. The question of HRU size and basis (e.g. land cover, topography, soils, etc.) may never be fully answered because the decision is driven by scale of analysis, type of application, type of model, study site, and data availability. Yet, guidelines for defining HRU's for use in the more popular models should be developed. 


\section{REFERENCE LIST}

Acevedo, William, 1991. "First Assessment of U. S. Geological Survey 30-Minute DEM's: A Great Improvement over Existing 1-Degree Data," Technical Papers, American Congress on Surveying and Mapping - American Society of Photogrammetry and Remote Sensing Annual Convention, Baltimore, Maryland, 1-12.

Battaglin, W. A, R. S. Parker, and L. E. Hay, 1992. "A Geographic Information System for Climate Studies in the Gunnison River Basin, Colorado," Abstracts of the American Water Resources Association Meetings, Reno, Nevada, 61.

Battaglin, William A., Lauren E. Hay, Randolph S. Parker, and George H. Leavesley, 1993. "Application of a GIS for Modeling the Sensitivity of Water Resources to Alterations in Climate in the Gunnison River Basin, Colorado," Proceedings of the American Water Resources Association Symposium on Geographic Information Systems and Water Resources, Mobile, Alabama, 203-210.

Becker, A., and B. Pfeutzner, 1990. "Large-scale Hydrological Modelling for Regional Transferring of Hydrological Information," Regionalization in Hydrology, International Association of Hydrological Sciences, 191:1 61-68.

Bedient, Philip B., 1988. Hydrology and Floodplain Analysis, Addison-Wesley, New York, New York.

Bicknell, Brian R., John C. Imhoff, John L. Kittle, Jr., Anthony S. Donigian, Jr., Robert C. Johanson, and Thomas O. Barnwell, 1992. Hydrologic Simulation Program - Fortran User's Manual for Release 10, U. S. Environmental Protection Agency, Athens, Georgia.

Biswas, Asit K., 1975. "A Short History of Hydrology," Selected Works in Water Resources, International Water Resources Association, 57-79.

Bliss, Norman, 1990. "A Hierarchy of Soil Databases for Calibrating Models of Global Climate Change," Soils and the Green House Effect, Wiley \& son, New York, New York. 
Bower, David E., 1985. "Evaluation of the Precipitation-Runoff Modeling System, Beaver Creek Basin, Kentucky," U. S. Geological Survey Water-Resources Investigations Report 84-4316.

Bregt, A. K., J. Denneboom, H. J. Gesink, and Y. Van Randen, 1991. "Determination of Rasterizing Error: A Case Study with the Soil Map of The Netherlands," International Journal of Geographical Information Systems, 5:3 361-367.

Burrough, P. A., 1986. Principles of Geographical Information Systems for Land Resources Assessment, Clarendon Press, Oxford, England.

Buttenfield, Barbara P., and Robert B. McMaster, 1991. Map Generalization: Making Rules for Knowledge Representation, John Wiley, New York, New York.

Carey, William P., and Andrew Simon, 1984. "Physical Basis and Potential Estimation Techniques for Soil Erosion Parameters in the PrecipitationRunoff Modeling System (PRMS)," U. S. Geological Survey Water-Resources Investigations Report 84-4218.

Carrigan, Jr., P. H., George R. Dempster, Jr., and David E. Bower, 1977. "User's Guide for U. S. Geological Survey Rainfall-Runoff Models--Revision of Open-File Report 74-33," U. S. Geological Survey Open-File Report 77-884.

Carroll, Crista, S., 1992. "Resource Management and Global Change Monitoring Using Biophysical Land Units (BLU)," Technical Papers: American Society of Photogrammetry and Remote Sensing / American Congress on Surveying and Mapping Conference, Washington, D. C., 5:1 12-15.

Carter, James R., 1989. "Relative Errors Identified in USGS Gridded DEMS," Proceedings: AUTO CARTO 9, Baltimore, Maryland, 255-265.

Cary, Lawrence E., 1984. "Application of the U.S. Geological Survey's Precipitation Modeling System to the Prairie Dog Creek Basin, Southeastern Montana," U. S. Geological Survey Water-Resources Investigations Report, 84-4178.

Catts, David, 1990. "Generalization of GIS Digital Data," Papers and Proceedings: Applied Geography Conference, Charlotte, North Carolina, 13:1 33-36.

Cavadias, G. S., 1990. "The Canonical Correlation Approach to Regional Flood Estimation," Regionalization in Hydrology, International Association of Hydrological Sciences, 191:1 171-178. 
Chairat, Sihem, and Jacques W. Delleur, 1993. "Effects of the Topographic Index Distribution on the Predicted Runoff Using GRASS," Proceedings of the American Water Resources Association Symposium on Geographic Information Systems and Water Resources, Mobile, Alabama, 285-292.

Chow, Ven Te, 1975. "Hydrologic Modeling," Selected Works in Water Resources, International Water Resources Association, 81-107.

Chrisman. Nicholas R., 1988. "The Risks of Software Innovation: a Case Study of the Harvard Computer Lab," The American Cartographer, 15:3 291-300.

Chrisman, Nicholas R., 1989. "Modeling Error in Overlaid Categorical Maps," Accuracy of Spatial Databases, Taylor and Francis, New York, New York, 2134.

Cohen, Stewart J., 1986. "Impacts of $\mathrm{CO}_{2}$-Induced Climatic Change on Water Resources in the Great Lakes Basin," Climatic Change, 8:1 135-153.

Coppock, J. T., and D. W. Rhind, 1991. "The History of GIS," Geographic Information Systems: Principles and Applications, Longman, London, England, 1:1 21-43.

Dawdy, D. R., J. C. Schaake, Jr., and W. M. Alley, 1978. Distributed Routing Rainfall-Runoff Model," U. S. Geological Survey Water Resources Investigations 78-90, $151 \mathrm{p}$.

DeCola, L., 1991. "Fractal Analysis of Multiscale Spatial Autocorrelation Among Point Data," Environment and Planning A, 23:1 545-566.

Duchon, Claude E, Jayne M. Salisbury, T. H. Lee Williams, and Arlin D. Nicks, 1992. "An Example of Using Landsat and GOES Data in a Water Budget Model," Water Resources Research, 28:2 527-538.

Eash, David A., 1993. "A Geographic In formation System Procedure to Quantify Physical Basin Characteristics," Proceedings of the American Water Resources Association Symposium on Geographic Information Systems and Water Resources, Mobile, Alabama, 173-182.

Eagleson, Peter S., 1985. "The Emergence of Global-Scale Hydrology," Chester C. Kisiel Memorial Lecture No. 4, Department of Hydrology and Water Resources, University of Arizona.

England, C. B., $1970 . \quad$ "Land Capability: A Hydrologic Response Unit in Agricultural Watersheds," Agricultural Research Service Publication, ARS 41-172. 
England, C. B., and H. N. Holtan, 1969. "Geomorphic Grouping of Soils in Watershed Engineering," Journal of Hydrology, 7:1 217-225.

Faucher, Claude, Peter Spal, Kaz Adamowski, Steve Enns, K. David Harvey, Robert Leconte, David W. Mullins, Pat Tang, and Ron Hudson, 1993. "A Hydrologic Model Designed to Make Use of Remotely Sensed and GIS Data," Proceedings of the American Water Resources Association Symposium on Geographic Information Systems and Water Resources, Mobile Alabama, 231-240.

Fellows, Jack D., and Robert M. Ragan, 1986. "The Role of Cell Size in Hydrology Oriented Geographic Information Systems," Hydrologic Applications of Space Technology, International Association of Hydrological Sciences, 160:1 453460.

Fleming, George, 1975. Computer Simulation Techniques in Hydrology, Elsevier, New York, New York.

Fontaine, Richard A., 1989. "Application of a Precipitation Modeling System in the Bald Mountain Area, Aroostook County Maine," U. S. Geological Survey Water Resources Investigations Report 87-4221.

Garbrecht, Jurgen, and Lawrence Martz, 1993. "Case Application of the Automated Extraction of Drainage Network and Sub-watershed Characteristics from Digital Elevation Models by DEDNM," Proceedings of the American Water Resources Association Symposium on Geographic Information Systems and Water Resources, Mobile, Alabama, 221-230.

Gates, W. Lawrence, 1985. "The Use of General Circulation Models in the Analysis of the Ecosystem Impacts of Climatic Change," Climatic Change, 7:1 267-284.

GIS World, 1992. "The 1991 GIS Industry Survey: Industry Summary," 1991-92 International GIS Sourcebook, 3:1 8-19.

Gleick, Peter H., 1987a. "Regional Hydrologic Consequences of Increases in Atmospheric $\mathrm{CO}_{2}$ and Other Trace Gases," Climatic Change, 10:1 137-161.

Gleick, Peter H., 1987b. "The Development and Testing of a Water Balance Model for Climate Impact Assessment: Modeling the Sacramento Basin," Water Resources Research, 23:6 1049-1061.

Goodchild, Michael F., 1980. "The Effects of Generalization in Geographical Data Encoding," Map Data Processing, Academic Press, New York, New York, 191-205. 
Goodchild, Michael F., and Sucharita Gopal, 1989. Accuracy of Spatial Databases, Taylor \& Francis Ltd., New York, New York.

Goodchild, Michael F., 1989. "Modeling Errors for Remotely Sensed Data Input to GIS," Proceedings of Auto Carto 9, Baltimore, Maryland, 530-537.

Gunderson, R. W., 1992. "A Self-Organizing Technique for Partitioning and Characterizing Watersheds for Distributed Parameter Modeling," Proceedings of the American Water Resources Association Meetings, Reno, Nevada, 3.

Hay, Lauren E., Mark D. Branson, and George H. Leavesley, 1992. "Simulation of Precipitation in the Gunnison River Basin Using an Orographic-Precipitation Model," Proceedings, American Water Resources Association Meetings, Reno, Nevada, 651-660.

Holtan, H. N., 1969. "Hydrologic Research for Watershed Engineering," Journal of Hydrology, 8:1 207-216.

Hutchinson, Michael F., 1991. "A Continental Hydrological Assessment of a New Grid-Based Digital Elevation Model of Australia," Hydrological Processes, 5:1 45-58.

International Geophysical Biophysical Programme, 1991. "Plant-Water Interactions in Large-Scale Hydrological Modelling," Global Change Report No. 17.

Jensen, John R., 1986. Introductory Digital Image Processing, Prentice-Hall, Englewood Cliffs, New Jersey.

Jensen, M. E., and H. R. Haise, 1963. "Estimating Evapotranspiration from Solar Radiation: Proceedings of the American Society of Civil Engineers," Journal of Irrigation and Drainage, 89:IR4 15-41.

Jensen, M. E., D.C. N. Rob, and C. E. Franzoy, 1969. "Scheduling Irrigations using Climate-Crop-Soil Data," Proceedings of the National Conference on Water Resources Engineering of the American Society of Civil Engineers, New Orleans, Louisiana.

Jenson, S. K., and J. O. Domingue, 1988. "Extracting Topographic Structure from Digital Elevation Data for Geographic Information System Analysis," Photogrammetric Engineering \& Remote Sensing, 54:11 1593-1600.

Jenson, S. K., 1992. "The Availability of Global Digital Topographic Data," Approved U. S. Geological Survey Abstract. 
Jeton, Anne E., and J. LaRue Smith, 1992. "Sensitivity of Windward and Leeward Watersheds in the Sierra Nevada Climate Change -- Part I, Development and Calibration of a Precipitation-Runoff Model and Application of a Geographic Information System," Water Resources Investigation Report, in review.

Jeton, Anne E., and J. LaRue Smith, 1993. "Development of Watershed Models for Two Sierra Nevada Basins Using a Geographic Information System," Proceedings of the American Water Resources Association Symposium on Geographic Information Systems and Water Resources, Mobile, Alabama, 251258.

Johnston, R. J., 1986. Multivariate Statistical Analysis in Geography, John Wiley \& Sons, Inc., New York, New York.

Jones, John, 1990, "An Evaluation of Watershed Characteristics Generated from various Digital Elevation Sources," Approved U. S. Geological Survey Abstract.

Kelmelis, John A., and Raymond D. Watts, 1991. "Terrestrial Process Modeling -A Challenge for Cartographers," Technical Papers of the American Congress on Surveying and Mapping - American Society of Photogrammetry and Remote Sensing Annual Convention, Baltimore, Maryland, 2:1 141-149.

Kuhn, Gerhard, and R. S. Parker, 1992. "Transfer of Watershed-Model Parameter Values to Non-calibrated Basins in the Gunnison River Basin, Colorado," Proceedings of the American Water Resources Association Meetings, Reno, Nevada, 741-750.

Leavesley, G. H., 1973. "A Mountain Watershed Simulation Model: unpublished PhD Dissertation, Department of Earth Resources, Colorado State University, Fort Collins, Colorado.

Leavesley, G. H. , R. W. Lichty, B. M. Troutman, and L. G. Saindon, 1983. "Precipitation-Runoff Modeling System: User's Manual," U. S. Geological Survey Water Resources Investigations, 83-4238.

Leavesley, G. H., M. D. Branson, and L. E. Hay, 1992a. "Using Coupled Atmospheric and Hydrologic Models to Investigate the Effects of Climate Change in Mountainous Regions," Proceedings of the American Water Resources Association Meetings, Reno, Nevada, 691-700.

Leavesley, G. H., P. Restrepo, L. G. Stannard, and M. Dixon, 1992b. "The Modular Hydrologic Modeling System - MHMS," Approved extended abstract, U.S. Geological Survey, Denver, CO. 
Linsley, Ray K., 1975. "The Relation Between Rainfall and Runoff," Selected Works in Water Resources, International Water Resources Association, 131-145.

Liverman, Diana, and Karen O'Brien, 1989. "The Impacts of Global Warming in Mexico," unpublished manuscript from the University of Wisconsin.

Loveland, Thomas, 1991. "Development of a Land-Cover Characteristics Database for the Conterminous U. S.," Photogrammetric Engineering \& Remote Sensing, 57:11 1453-1463.

Luker, Steve, Scott A. Samson, and William W. Schroeder, 1993. "Development of a GIS Based Hydrologic Model for Predicting Direct Runoff Volumes," Proceedings of the American Water Resources Association Symposium on Geographic Information Systems and Water Resources, Mobile, Alabama, 303312.

Lumb, Alan M., Richard B. McCammon, and John L. Kittle, Jr., 1992. "User's Manual for an Expert System for Watershed Model Calibration," $U$. S. Geological Survey Water-Resources Investigations Report, in review.

MacEachren, Alan M., 1987. "Sampling and Isometric Mapping of Continuous Geographic Surfaces," The American Cartographer, 14:4 299-320.

Maffini, Giulio, 1987. "Raster versus Vector Data Encoding and Handling: A Commentary," Photogrammetric Engineering \& Remote Sensing, 53:10 13971398.

Mancini, M., and R. Rosso, 1989. "Using GIS to Assess Spatial Variability of SCS Curve Number at the Basin Scale," New Directions for Surface Water Modeling, International Association of Hydrological Sciences, 181:1 435-444.

Martz, Lawrence W., and Jurgen Garbrecht, 1993. "DEDNM: A Software System for the Automated Extraction of Channel Network and Watershed Data from Raster Digital Elevation Models," Proceedings of the American Water Resources Association Symposium on Geographic Information Systems and Water Resources, Mobile, Alabama, 211-220.

Moellering, H., and W. Tobler, 1972. "Geographical Variances," Geographical Analysis, 4:1 34-50.

Moore, I. D., R. B. Grayson, and A. R. Ladson, 1991. "Digital Terrain Modelling: A Review of Hydrological, Geomorphological and Biological Applications," Hydrological Processes, 5:1 3-30. 
Moreau, David. "Climate Change and Water Supply," Department of City and Regional Planning, University of North Carolina at Chapel Hill, North Carolina.

Mounsey, Helen, and Roger F. Tomlinson, 1988. Building Databases for Global Science, Taylor \& Francis, Ltd, London, England.

Muller, J-C., 1991. "Generalization of Spatial Databases," Geographic Information Systems: Principles and Applications, Longman, London, England, 1:1 457475.

Nicks, A. D., and F. R. Schiebe, 1992. "Using NEXRAD Precipitation Data as Input to Hydrologic Models," Proceedings of the American Water Resources Association Meetings, Reno, Nevada, 75-83.

Openshaw, S., 1984. "The Modifiable Areal Unit Problem," Concepts and Techniques in Modern Geography Volume 38.

Osborn, Herbert B., and J. Roger Simanton, 1990. "Hydrologic Modeling of a Treated Rangeland Watershed," Journal of Range Management, 43:6 474-481.

Parker, R. S., and J. M. Norris, 1989. "Simulation of Streamflow in Small Drainage Basins in the Southern Yampa River Basin, Colorado," U. S. Geological Survey Water Resources Investigations Report 88-4071.

Peck, Dallas, L., 1993. "Keynote Speech: Geographic Information Systems and Water Resources,: Proceedings of the American Water Resounces Association Symposium on Geographic Information Systems and Water Resources, Mobile, Alabama, 1-7.

Peucker, Thomas K., 1979. "Digital Terrain Models: An Overview," Proceedings of AUTO CARTO IV, Reston, Virginia, 97-107.

Pick, Thomas A., 1987. "DEM Data Used to Develop Runoff in Areas of Depressional Storage," Proceedings of the First International Conference on Computational Hydrology, Anaheim, California, J1-J7.

Pilotti, M., and R. Rosso, 1990. "SHELL: A General Framework for Modelling the Distributed Response of a Drainage Basin," Proceedings of the Eighth International Conference on Computational Methods in Water Resources, Venice, Italy, 517-522.

Robinson, Arthur H., Randall D. Sale, Joel L. Morrison, and Phillip C. Muehrcke, 1984. "Simplification and Classification Processes," Elements of Cartography, John Wiley and Sons, New York, New York. 
Ryan, Thomas P., 1992. "Integration of a Reservoir Routing Model and Data Management System with a Physically Based Watershed-Model in the Gunnison River Basin," Proceedings of the American Water Resources Association Meetings, Reno, Nevada, 90.

Salisbury, Jayne, 1992. Basin Controls and Hydrologic Response in the Little Washita Watershed, Oklahoma, unpublished dissertation from the University of Oklahoma.

Sinton, David F., 1992. "Reflections on 25 Years of GIS," GIS World, 5:1 8 page supplement.

Smith, J. LaRue, and Brian D. Reece, 1992. "Watershed Characterization for the Precipitation-Runoff Modeling System: North Fork American River and East Fork Carson River, California," U. S. Geological Survey Water Resources Investigation Map Report, in review.

Stephenson, G. R., and C. B. England, 1969. "Digitized Physical Data of a Rangeland Watershed," Journal of Hydrology, 8:1 442-450.

Steyaert, Louis, T., Thomas R.Loveland, Jesslyn F. Brown, and Bradley C. Reed, 1993. "Integration of Environmental Simulation Models with Satellite Remote Sensing and Geographic Information Systems Technologies: Case Studies." Pecora Symposium Proceedings, Sioux Falls, South Dakota.

Swift, Lloyd, W., 1976. "Algorithm for Solar Radiation on Mountain Slopes," Water Resources Research, 12:1 108-112.

Theobold, David M., 1989. "Accuracy and Bias Issues in Surface Representation," Accuracy of Spatial Databases, Taylor and Francis, New York, New York, 99113.

Thomas, Richard P., 1990. "Application of The DR3M Watershed Model on a Small Urban Basin," Water Resources Bulletin, 26:5 757-766.

Tobler, Waldo, 1966. "Numerical Map Generalization," Michigan University Community of Mathematical Geographers, Discussion Paper Number 8.

Tobler, Waldo, 1988. "Resolution, Resampling, and all that," Building Databases for Global Science, Taylor \& Francis, New York, New York, 129-137.

U. S. Geological Survey, 1986. "Land Use and Land Cover Digital Data from 1:250,000- and 1:100,000-Scale Maps," U. S. Geological Survey Data User's Guide 4, Reston, Virginia. 
U. S. Geological Survey, 1990. "Digital Elevation Models," U. S. Geological Survey Data User's Guide 5, Reston, Virginia.

U. S. Geological Survey, 1992. "Spatial Data Transfer Standard," Federal Information Processing Standards Publication, U. S. Department of Commerce, National Institute of Standards and Technology, Gaithersburg, Maryland.

Weibel, R., and M. Heller, 1991. "Digital Terrain Modelling," Geographic Information Systems: Principles and Applications, Longman, London, England, 1:1 269-297.

Wiggins, Lyna L., William Craig, and Richard Langendorf, 1992. "IS/GIS Hardware/Software/Data Features and Capabilities: What's Done, What's On, What's Next?," Proceedings of the Urban and Regional Information Systems Association Annual Meeting, Washington, D. C., 59-84.

Williams, T. H. Lee, 1992. "Surface Hydrology Research Cluster: A Proposal Submitted to NSF EPSCoR Program," University of Oklahoma Research Proposal.

Wolock, D. M., and C. V. Price, 1992. "Effects of Resolution of Digital Elevation Data on a Topography-based Hydrologic Model," In Review at the U. S. Geological Survey, West Trenton, New Jersey.

Wood, Eric F., 1987. "Influence of Spatial Variability and Scale Effects on the Parameterization of Hydrologic Response," Final Technical Completion Report, USGS Grant No. 14080001 G1138, Department of Civil Engineering and Operations Research, Princeton University, Princeton, New Jersey.

Yoeli, Pinhas, 1983. "Digital Terrain Models and their Cartographic and Cartometric Utilisation," The Cartographic Journal, 20:1 17-22. 